\title{
Green Propellant Infusion Mission Program Development and Technology Maturation
}

\author{
Christopher H. McLean ${ }^{1}$, William D. Deininger ${ }^{2}$, and John Joniatis ${ }^{3}$ \\ Ball Aerospace \& Technologies Corporation, Boulder, CO 80301 \\ Pravin K. Aggarwal ${ }^{4}$ \\ NASA Marshall Space Flight Center, Huntsville, AL 35812 \\ Ronald A. Spores ${ }^{5}$ \\ Aerojet Rocketdyne Redmond, WA 98052 \\ Matthew Deans ${ }^{6}$, John T. Yim ${ }^{7}$, and Kristen Bury ${ }^{8}$ \\ NASA Glenn Research Center Cleveland, OH 44135 \\ Jonathan Martinez ${ }^{9}$ \\ NASA Kennedy Space Center Kennedy Space Center, FL 32899 \\ and \\ Eric H. Cardiff ${ }^{10}$, and Caitlin E. Bacha ${ }^{11}$ \\ NASA Goddard Space Flight Center, Greenbelt, MD 20771
}

\begin{abstract}
The NASA Space Technology Mission Directorate's (STMD) Green Propellant Infusion Mission (GPIM) Technology Demonstration Mission (TDM) is comprised of a cross-cutting team of domestic spacecraft propulsion and storable green propellant technology experts. This TDM is led by Ball Aerospace \& Technologies Corp. (BATC), who will use their BCP100 spacecraft to carry a propulsion system payload consisting of one $22 \mathrm{~N}$ thruster for primary divert $(\Delta V)$ maneuvers and four $1 \mathrm{~N}$ thrusters for attitude control, in a flight demonstration of the AF-M315E technology. The GPIM project has technology infusionteam members from all three major market sectors: Industry, NASA, and the Department of Defense (DoD). The GPIM project team includes BATC, includes Aerojet Rocketdyne (AR), Air Force Research Laboratory, Aerospace Systems Directorate, Edwards AFB (AFRL), NASA Glenn Research Center (GRC), NASA Kennedy Space Center (KSC), and NASA Goddard Space Flight Center (GSFC). STMD programmatic and technology oversight is provided by NASA Marshall Space Flight Center. The GPIM project shall fly an operational AF-M315E green propulsion subsystem on a Ball-built BCP-100 spacecraft.
\end{abstract}

${ }^{1}$ GPIM Principal Investigator, 1600 Commerce Street, Boulder, CO 80305, Senior Member AIAA.

${ }^{2}$ Chief Systems Engineer, 1600 Commerce Street, Boulder, CO 80305, Associate Fellow AIAA.

${ }^{3}$ GPIM Program Mananger, 1600 Commerce Street, Boulder, CO 80305.

${ }^{4}$ Chief Engineer, TDM Program Office, NASA-MSFC, Al-35812, Associate Fellow AIAA.

${ }_{6}^{5}$ Aerojet Rocketdyne PM for GPIM, 11411 Willows Rd NE, Redmond, WA 98052, Senior Member AIAA.

${ }^{6}$ Aerospace Engineer, Ascent and Thermal Propulsion Branch, NASA-GRC, 21000 Brookpark Road MS 301-2, Cleveland, $\mathrm{OH} 44135$, Member AIAA.

7 Aerospace Engineer, In-Space Propulsion Systems Branch, NASA-GRC, 21000 Brookpark Road MS 86-8, Cleveland, $\mathrm{OH} 44135$, Member AIAA.

${ }^{8}$ Electrical Engineer, Power Architecture and Analysis Branch, NASA-GRC, 21000 Brookpark Road MS 142-6, Cleveland, $\mathrm{OH} 44135$.

${ }_{9}^{9}$ Aerospace Engineer, Fluids and Propulsions Division, MC NE-F4 Kennedy Space Center, FL 32899.

${ }^{10}$ Senior Propulsion Engineer, NASA GSFC, 8800 Greenbelt Rd., Greenbelt MD 20771, Senior Member AIAA.

${ }^{11}$ Associate Branch head, NASA GSFC, 8800 Greenbelt Rd., Greenbelt MD 20771, Member AIAA. 


\section{Introduction}

Green Propellant Infusion Mission (GPIM) is a project in the NASA Technology Demonstration Mission (TDM) J program office at Marshall Space Flight Center (MSFC) ${ }^{1,2,3}$. The TDM program office manages demonstration projects bridging the gap between technology development and the infusion of system-level technologies into missions undertaken by NASA, Department of Defense, and industry. The GPIM project will perform a spaceflight demonstration of a new green propulsion system. This technology promises higher performance for future satellites by providing options for longer mission durations, additional maneuverability, increased payload, and simplified launch processing. The green propellant for this mission is AF-M315E, a blend of hydroxylammonium nitrate (HAN) and other ingredients, ${ }^{4,5,6,7,8}$. Developed by Air Force Research Laboratory (AFRL), it offers nearly 50 percent higher performance for a given propellant tank volume compared to a standard hydrazine system. During the course of the GPIM project both $1 \mathrm{~N}$ and $22 \mathrm{~N}$ thrusters will be matured, flight qualified, and flown. In addition to the maturation of the thrusters, all wetted components will be matured/redesigned then requalified for compatibility with AF-M315E, resulting in a complete propulsion subsystem demonstration to allow for the infusion of this technology into the market as an alternate to hydrazine based systems currently used for spacecraft reaction control system (RCS).

Once on orbit, the project will demonstrate the use of the selected green propellant and characterize its flight performance using standard Ball Aerospace flight control algorithms. In addition, the mission will use a BCP-100 spacecraft (SC) bus to validate the benefits of the non-toxic fuel for future satellite missions ${ }^{9}$. Ball's BCP-100 spacecraft bus features standard payload interfaces, robust power and thermal design for any LEO orbit, and heritage Command and Data Handling (C\&DH) system. The upper deck of the GPIM BCP-100 bus will be provided to Aerojet Rocketdyne (AR), who will build and integrate the AF-M315E propulsion subsystem to this interface and deliver it to Ball Aerospace for integration onto the BCP-100 bus. In addition to the core green propellant technology demonstration, and advanced Multi-Layer Insulation (MLI) technology, Integrated MLI (IMLI), will be flown, raising the maturity of this product to TRL 8 .

Currently the GPIM spacecraft bus is nearing completion. The BCP-100 is an assembly of five component panels, with the sixth side of the bus being the Payload Interface Platform (PIP). The PIP was used as the structural platform for the assembly of the propulsion payload. When complete, the propulsion subsystem assembly will be delivered to Ball and integrated into the BCP-100 bus. Currently all of the other BCP-100 component panels are complete and assembled, and the propulsion payload is in final assembly at AR.

One of the critical activities associated with the implementation of a new propellant is the process of getting approval from Range Safety for the handling, storage, and loading of the propellant. A major milestone in the GPIM project occurred at the 45th Space Wing Preliminary Range Safety Meeting, with the acceptance of AF-M315E, with a reduction in hazard classification from 'catastrophic' to 'critical' (compared to standard space-storable propellants). This hazard classification reduction results in relaxed requirements for personal protection, handling, loading, and disposal of propellants.

AR has completed development of the Engineering Model $1 \mathrm{~N}$ thruster including performance mapping, life, and environmental testing. Performance testing was enhanced through the use of an AFRL thrust stand providing high fidelity $1 \mathrm{~N}$ thruster measurements during impulse bit mapping.

NASA's involvement in the GPIM project involves multiple centers, strategically leveraging the resources of GRC, KSC, and GSFC. In 2013, GRC developed AF-M315E thruster plume models, evaluating the impingement and deposition effects on the GPIM spacecraft. In 2014, GRC performed ground testing and plume diagnostics correlating the plume modeling with experimental data, and expanded the plume molding effort to evaluate plume impingement effects on the GPIM solar arrays. NASA KSC is preforming testing of titanium samples from an ATK/PSI provided propellant tank for fracture mechanics, which will provide the input required to perform analysis verifying leak-before-burst for this propellant/tank configuration. KSC also developed requirements and procedures for the receivable, storage, and transportation of AF-M315E at the range. NASA GSFC supported review of the overall propulsion subsystem design and AI\&T processes, will provide test and analytical support for launchinduced and flight slosh dynamics, and will performing water hammer and cold flow testing for a representative GPIM propulsions subsystem and specific components.

\section{Project Construct}

\section{A. Project Team}

The GPIM project is managed by a Project Manager from Ball Aerospace with a cross-cutting team of domestic spacecraft propulsion and green technology experts, Figure 1, with oversight from the TDM program office at 
MSFC. The Project Manager has full responsibility for the success of the technology demonstration mission. Ball provides the BCP-100 bus, as well as performing assembly, integration, and test (AI\&T) of the completed GPIM space vehicle (SV). Overall day-to-day program management is also provided by Ball, as well as mission systems engineering and requirements development and verification. After environmental testing, Ball will ship the GPIM space vehicle to Cape Canaveral Air Force Station (CCAFS) to conduct pre-launch processing and turn over to SpaceX for integration onto the Falcon Heavy launch vehicle.

The Principle Investigator (PI), also at Ball Aerospace, is the overall architect of the mission. The PI coordinates the activity of all of the team members to insure that the technical objectives of the mission are achieved. The PI works hand in hand with the Project Manager and the Project Systems engineer to establish the Level 1 project requirements at the beginning of the project, ensure that those requirements are properly flowed down and complied with throughout the development effort, and are met at the conclusion of the mission demonstration.

GPIM will gain access to space as a rideshare payload via a launch service Memorandum of Agreement (MOA) with the Air Force Space and Missile Systems Center Space Development and Test Directorate (SMC/SDTD) on the Space Test Program-2 (STP-2) mission, separating at a nominal $720 \mathrm{~km}, 24-\mathrm{deg}$ inclination orbit. This is the second planned launch of Space-X's Falcon 9 heavy. Ball will manage all launch service integration activities, and is currently working to validate the compliance of AF-M315E with range safety requirements. Ball is responsible for also developing flight software to enhance the capabilities of the existing BCP-100 software to include heritage propulsion subroutines from other Ball SC, as well as developing unique code that allows for a $22 \mathrm{~N}$ thruster to perform primary divert maneuvers using thrust-vector control performed by pulse modulation of four $1 \mathrm{~N}$ thrusters.

AR has the first of the five Co-investigators (Co-I) on the GPIM project. During the course of this effort, AR will mature laboratory model AF-M315E $1 \mathrm{~N}$ and $22 \mathrm{~N}$ thrusters through engineering model (EM) and flight model (FM) designs. AR will provide a complete, integrated propulsion subsystem for integration onto a Ball Aerospace provided platform. In addition to the GPIM payload subsystem, AR is responsible for the completion of AF-M315E compatibility testing of all wetted components of a typical blow-down, elastomeric diaphragm tank propulsion system employed for spacecraft reaction control system (RCS).

At the end of this mission the GPIM spacecraft will achieve a Technology Readiness Level TRL of 7+, with the new propulsion components achieving a TRL of 8 . In addition, Aerojet will have full qualification of both the thrusters, via on-orbit demonstration, allowing for a direct infusion of the green propellant based RCS thrusters of 1 $\mathrm{N}$ and $22 \mathrm{~N}$ class into the spacecraft community.

NASA Glenn Research Center (GRC) has the second of the five Co-Is on the GPIM project and is responsible for developing $1 \mathrm{~N}$ and $22 \mathrm{~N}$ thruster plume models based on theoretical chemical equilibrium predictions for the AF-M315E propellant. A GPIM SV-level plume model is being developed to evaluate plume impingement/interactions ${ }^{11,12}$. Analysis of the plume effects on the solar arrays is a secondary effort and will be started in FY 2014. Verification of the model predictions will be performed by testing of an AR engineering model $22 \mathrm{~N}$ thruster in a GRC test facility modified for operation with AF-M315E.

The GRC facility modifications include a dedicated AF-M315E feed system, a temperature-controlled propellant storage facility, and a back-illuminated intensified charge-coupled device (ICCD) camera which offers as much as 1000 times the sensitivity of conventional ICCDs. These modifications have been partially funded by NASA GRC. Planned testing includes both steady-state and pulse-mode operation of the thruster. Several plume diagnostic measurement techniques will be employed including Rayleigh and Raman Spectroscopy and Schlieren imaging to measure temperature, velocity and total density in the plume field flow as well as species concentration. Results of the plume measurements will be compared to the plume models.

AFRL is the third of the five Co-Is on the GPIM project. Under the GPIM effort, work will continue in the areas of hazard analysis, Department of Transportation (DOT) classification for the propellant, and support of range safety compliance. AFRL will also supply the propellant for all aspects of the GPIM program: flight propellant, propellant for all ground testing at Aerojet, propellant for the NASA GRC plume diagnostics testing, and propellant to NASA KSC for fracture mechanics materials exposure. AFRL is designing and fabricating the propellant loading ground support equipment (GSE), and is responsible for the fueling of the GPIM Space Vehicle. 




Figure 1-GPIM Team. Cross-cutting team includes all relevant technology stake-holders; NASA, DoD, and industry.

NASA KSC is the fourth Co-I for the program. KSC is leveraging its expertise in RCS propellant storage and handling from the Space Shuttle program, fluids and materials analysis capabilities, and advanced spacecraft thermal insulation technologies. KSC will be supporting the development of the AF-M315E safety documentation to allow for handling by NASA, and will also study simplifications in the transportation, storage, and handling of the propellant on the range and within NASA facilities. Specific to spacecraft processing and range safety issues, KSC will participate in the development of methods for loading and detanking AF-M315E and look for areas to reduce cost and operational risk, and address decontamination issues. In addition to these activities, KSC will evaluate the ability to perform propellant assay analysis using existing facilities.

In addition to the propellant evaluation activities, NASA KSC is performing threshold stress intensity testing and analysis on propellant tank samples immersed in AF-M315E per the requirements of ASTM E1681. These data will be used to perform NASGRO fracture mechanics analysis of representative tank samples provided by ATK/PSI specifically for this program.

NASA GSFC is the fifth and final Co-I for the program. GSFC serves as a technical consultant on the propulsion system payload, providing insight and support into the propulsion system design and independent assessments of component-and system-level testing. GSFC is also participating on two main technical tasks. The first task is to develop test plans and supervise slosh testing of a tank simulator at Southwest Research Institute (SWRI) to quantify the expected slosh effects from the tanks. The second principal task is to perform surge testing to simulate pressure transients of GPIM during propulsions subsystem.

The Air Force Space and Missile Systems Center (SMC) is providing support for all mission operations at the Multi-Mission Satellite Operations Center (MMSOC), Kirtland Air Force Base. In addition to mission operations, SMC is providing Ground Support Equipment (GSE) to facilitate GPIM AI\&T activities.

The TDM program office at NASA Marshall Space Flight Center (MSFC) is providing contract management and project/engineering oversight of the overall GPIM contract. Additionally, MSFC has responsibility to conduct major project reviews using a Standing Review Board, and is also acting as the mission launch coordinator with support from Ball and coordinate/lead activities related to certification of readiness for flight demonstration.

\section{Project Phases}

The GPIM project is broken into three programmatic phases - Base Period, Option 1, and Option 2 - as shown in Figure 2. The Base Period runs through Critical Design Review (CDR) and will complete with the life and system level testing of the $1 \mathrm{~N}$ and $22 \mathrm{~N}$ thrusters. In addition, all major SV and long lead BCP-100 components and design/engineering activities will be completed.

The Option 1 period is for the development and qualification of an operational propulsion system and for assembly of the BCP-100 bus. The period culminates with an integrated GPIM propulsion subsystem completed at Aerojet.

During Option 2 the payload and BCP-100 are integrated to form the SV, the integrated SV is tested, launched, and operated for 81 days on orbit as shown in Figure 3. At the end of this mission the GPIM spacecraft will have 
demonstrated a Technology Readiness Level TRL of 7+, with the propulsion components achieving a TRL of 8 through full ground-based qualification testing.

\section{Program-Level Requirements}



Figure 2-The three contract phases of GPIM. GPIM program is currently in the middle of the Base Period, which will conclude with CDR in Q1 2014.

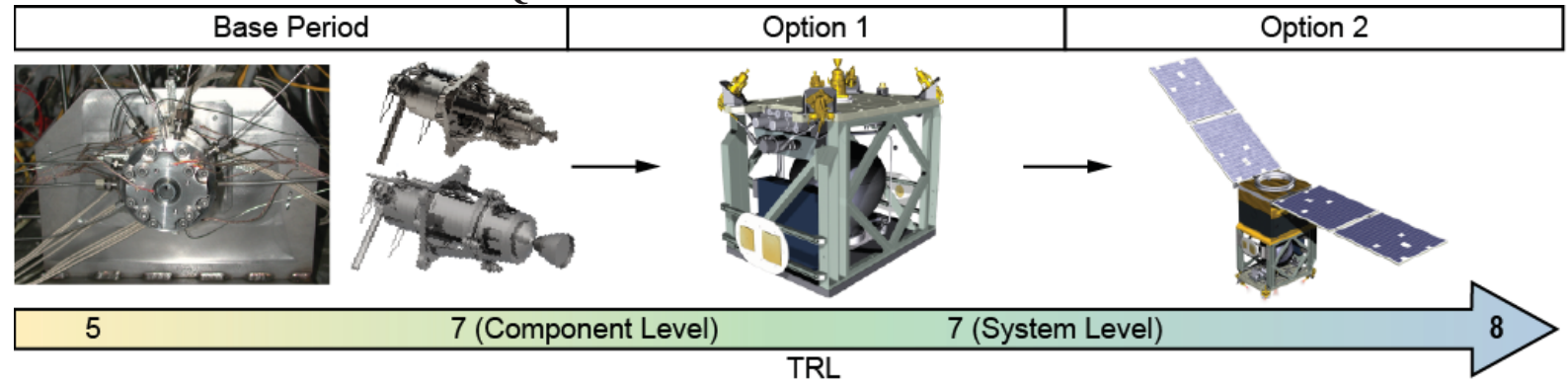

Figure 3-On-orbit demonstration overview. GPIM mission includes 21 days of checkout and 60 days of mission operation with a controlled re-entry.

Six program-level (or top-level) requirements are imposed on GPIM. These requirements were developed by the TDM program and the GPIM project to advance AF-M315E based green propulsion technology to a point where it could be directly infused into the appropriate market segments.

1. Propulsion system-The GPIM project shall demonstrate the on-orbit performance of a complete AF-M315E propulsion system suitable for an ESPA-class spacecraft.

The GPIM program will be demonstrated on a rideshare-class spacecraft. The propulsion subsystem is therefore sized, in terms of both propellant and thruster class, to meet the requirements of this type of mission.

2. Propellant performance-The GPIM project shall demonstrate AF-M315E steady-state performance of delivered volumetric impulse at least 40 percent greater than hydrazine.

Development data, based on the chemical properties and performance of a wide range of AF-M315E thrusters and engines, has demonstrated volumetric impulse performance that is 50 percent greater than hydrazine. Compliance to this requirement will be demonstrated with both the Flight Model (FM) $1 \mathrm{~N}$ and $22 \mathrm{~N}$ thrusters.

3. Attitude control thruster performance-The GPIM project shall demonstrate stable performance of a flightweight AF-M315E attitude control thruster for at least 10,000 total pulses.

This requirement is targeted specifically at the $1 \mathrm{~N}$ thrusters. The number of pulses exceeds that predicted for the worst case operational requirement in small spacecraft applications of the $1 \mathrm{~N}$ thruster by at least a factor of 1.5. Compliance with this requirement will be demonstrated during ground-based qualification testing. Early flight ADCS modeling also indicates that at least one of the four $1 \mathrm{~N}$ thrusters will demonstrate in excess of 10,000 pulses during flight operations.

4. Orbital maneuvering thruster performance-The GPIM project shall demonstrate stable performance of a flightweight AF-M315E primary propulsion thruster for propellant throughput of at least 7 kilograms.

This requirement is targeted specifically at the $22 \mathrm{~N}$ thruster. Compliance with this requirement will be demonstrated during ground-based qualification testing, and it is a program goal to also meet this requirement during on-orbit operations. The current Laboratory Model (LM) has already successful demonstrated a throughput of $9.4 \mathrm{kgs}$, and early flight ADCS modeling indicates that the $22 \mathrm{~N}$ thruster will consume in excess of $13 \mathrm{~kg}$ during flight operations. 
5. Spacecraft attitude control performance-Utilizing AF-M315E propellant, the GPIM project shall demonstrate three-axis spacecraft attitude control with a pointing accuracy of less than 6 degrees.

This requirement will be demonstrated on-orbit using just the $1 \mathrm{~N}$ attitude control thrusters. The BCP-100 momentum wheels and torque rods will be disabled for this portion of the mission. The accuracy of 6 degrees was selected based on the maximum allowable pointing error for acceptable telecommunications. It is anticipated that the demonstrated accuracy will be an order of magnitude better than the requirement.

6. Propellant operations assessment-The GPIM project shall produce a detailed report comparing all aspects of ground and on-orbit propellant operations for AF-M315E and hydrazine.

The cradle-to-grave operational impacts of an AF-M315E propulsion subsystem will be compared to that of a comparable hydrazine system.

\section{Propellant Classification and Range Safety}

\section{A. AF-M315E Hazard Classification}

In 2010, the Air Force was granted a 1.3C Final Hazard Classification (FHC) for packaged AF-M315E in two configurations ( 1 gallon and 5 gallon) by DOT ${ }^{13}$. However, in the last few years, both additional hazard testing on AF-M315E and changing views in hazard classification by DoT and DoD have given cause to re-evaluate the current hazard class designation of the packaged propellant.

The supplementary test data consisted of single package tests using a submerged blasting cap as an initiator and previous results from pan fire tests conducted by the Fire Sciences group at the Naval Air Warfare Center at China Lake. The results from these tests further illustrated the mild response of AF-M315E to both stimuli. The propellant exhibited no reaction to cap initiation in both containers. The substance also proved to be very difficult to ignite in the pan fire tests, requiring prolonged exposure to flame at ambient pressure and then only occasioning in a mild burn. Based upon results of these tests the DoD Joint Hazard Classifiers (JHC) and members of the Department of Defense Explosive Safety Board (DDESB) recommended of submittal a request by AFRL to Hazard Designation of $1.4 \mathrm{C}$, UN 0479 for this material. The DOT has granted a FHC of $1.4 \mathrm{C}$, UN 0479 by DOT in both the 5-gal (EX2010060551) and 1-gal (EX2010060549) packaging configurations to Air Force. This change to a lower hazard designation translates into a significant reduction in the costs and logistics associated with the storage and transportation of the propellant.

\section{B. Range Safety}

The GPIM project has held a preliminary Program Introduction meeting with the 45th Space Wing Range Safety Office. One of the primary goal of this meeting was to discuss the Range Safety Users Requirements AFSPC-MAN 91-710 document, and what advantages might be realized through the use of AF-M315E versus hydrazine in handling, loading, and propulsion subsystem design inhibits. Current hydrazine or hypergolic propulsion systems have a Range Safety hazard classification of "catastrophic." The GPIM project proposed that, based on the extensive work performed by AFRL characterizing AF-M315E, the hazard classification should be reduced to "critical" or "marginal." On-going discussion between the GPIM team and the 45th Space Wing has resulted in a hazard classification of this propellant as "critical", with the option for official reduction to "marginal" during the course of the GPIM program.

The implications of this "critical" rating include reduction in personal protection requirements from full Self Contained Atmospheric Protective Ensemble (SCAPE) suits (as required by standard propellants) to lab coats, gloves and splash guards. This rating also impacts the mechanical and electrical inhibit requirements for the GPIM propulsions systems design, as well as forward-going AF-M315E propulsion subsystems in general. All of these should result in substantive savings in comparison to the use of hydrazine as propellant.

\section{Propulsion Payload and Space Vehicle Overview}

\section{A. GPIM Propulsion Subsystem}

The GPIM demonstration payload subsystem illustrated in Figure 4 and shown in in Figure 5, is being developed as a self-contained module to allow independent assembly at Aerojet for subsequent integration into the bus, and is expected deliver 50\% more impulse than a comparably-packaged hydrazine system. Designed to attach to the Ball Aerospace BCP-100 bus via its standard payload interface plate (PIP), the propulsion subsystem comprises a simple, single-string, blow-down AF-M315E advanced green monopropellant propulsion system employing four $1 \mathrm{~N}$ attitude-control thrusters and a single $22 \mathrm{~N}$ primary divert thruster. 

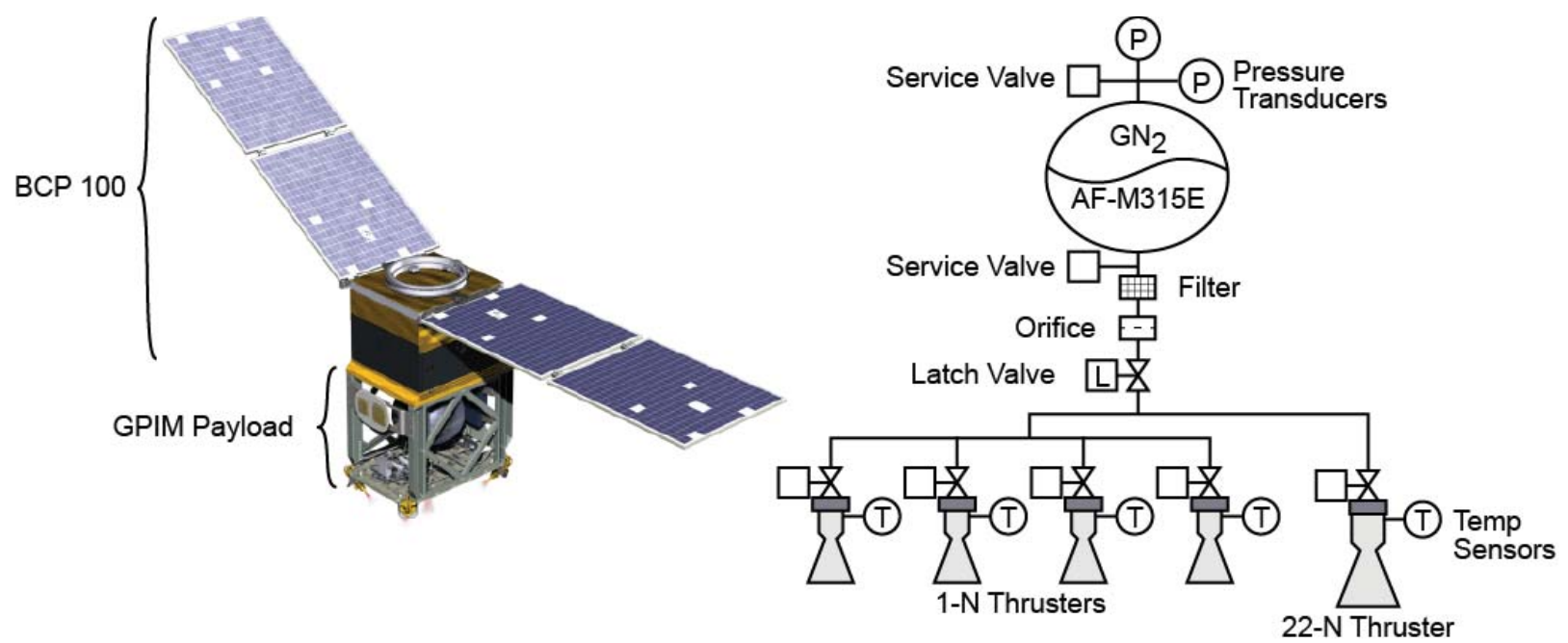

Ball GPIM Space Vehicle leverages flight heritage bus, AF-M315E propulsion subsystem

The propulsion subsystem provides dual isolation redundancy and instrumentation to fully characterize the system on-orbit

Figure 4-GPIM Space Vehicle and propulsion subsystem schematic. GPIM mission leverages flight heritage Ball BCP-100 bus and AF-M315E propulsion subsystem.

The propellant feed manifold's principal components consisting of: a standard diaphragm propellant tank, latch valve, and service valves, represent all flight-proven (TRL 9 with hydrazine propellant) designs selected specifically for the long-term compatibility of their materials of construction with AF M315E. In addition, pressure transducers are included to monitor gas-side propellant tank pressure (and hence propellant consumption). Thrusters are mounted on the upper deck of a box-like payload primary structure. The $22 \mathrm{~N} \Delta \mathrm{V}$ thruster is mounted on the spacecraft centerline with the thrust axis pointed through the PIP-mounted propellant tank and spacecraft center of mass.

The four $1 \mathrm{~N}$ thrusters are canted on brackets at the corners of the upper deck to maximize the moment arm to the spacecraft center of mass, and thereby control authority and resolution of impulse measurement by the bus attitude and orbit determination and control (AODC) sensors. The remaining propulsion system components are consolidated on a component panel attached to the underside of the upper deck, except for the two service valves, which mount to a separate bracket positioned for easy access during fueling and range operations.

Design considerations for the AF-M315E propulsion system are similar to a traditional hydrazine system, with a few special considerations. The general schematic layout is identical to single string blow-down hydrazine systems commonly employed on small spacecraft. Similarly, many of the other general design guidelines of hydrazine system are being applied in design construction of the propulsion subsystem.

The AF-M315E system as discussed previously is far less hazardous, "critical", than a traditional hydrazine system when considering range safety requirements. The propellant is far less prone to leakage (due to higher viscosity), is non-toxic if leaked, and the thrusters cannot inadvertently fire since preheating of catalyst beds is required. Per Range Safety AFSPCMAN 91710 requirements, a classification of "critical" or less only requires a two-seal inhibits to external leakage; hence no additional latch valves or other isolation device are required in the feed system despite the fact that the advanced monopropellant thrusters employ only single-seat valves. This approach reduces the complexity, power, mass and volume of the thruster valve, while simplifying electrical interfaces, all without sacrificing mission reliability. 
Two types of insulation are employed for the propulsion subsystem. The 'propulsion deck', or upper mounting plate for the five thrusters, is covered with a Ball heritage high temperate MLI. The four sides of the payload employ IMLI, an advanced MLI technology developed by Ball and its partners over the past decade. The IMLI is riding as technology demonstration and will achieve TRL 8 with the GPIM project.

\section{B. Space Vehicle Overview}

The GPIM Project space vehicle (SV) is based on a BCP-100 spacecraft Bus. The Ball BCP-100 platform is the commercial version of the Space Test Program (STP) Standard Interface Vehicle (SIV) developed by the Space Development and Test Directorate (SDTD) of the USAF Space and Missile Systems Center (SMC) ${ }^{14,15,16,17}$. Rather than designing a unique spacecraft for each payload; the BCP-100 is a recurrent spacecraft Bus with adaptable interfaces to accommodate a range of payloads. The baseline BCP-100 spacecraft Bus has power and data resources to accommodate one to

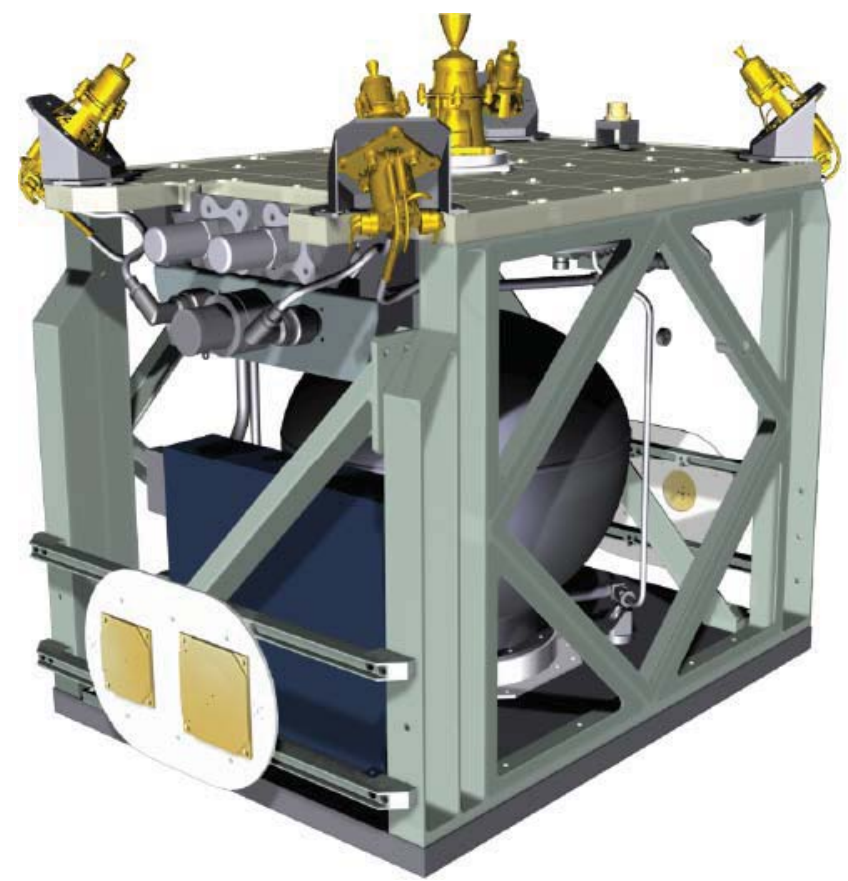

Figure 5-AF-M315E propulsion system.

four payloads totaling up to $70 \mathrm{~kg}$ mass and $200 \mathrm{~W}$ orbit average power mounted to an external payload interface plate (PIP). The BCP-100 spacecraft Bus features standard payload interfaces, robust power and thermal design for any LEO orbit, and heritage Command and Data Handling (C\&DH) system. The first BCP-100, STPSat-2, launched on November 19, 2010 and has surpassed 3 years on-orbit while STPSat-3 is well into its first year on-orbit since launch on November 19, 2013. The GPIM SV, Figure 4, is the third build of this platform and carries the propulsion subsystem as the primary payload.

The heritage BCP-100 spacecraft Bus does not include propulsion. The BCP-100 platform is adapted as part of the GPIM Project to accommodate a propulsion system and enable its safe operation through all mission phases. This entails developing mission-specific ADCS algorithms to provide high accuracy attitude measurements and precise control of GPIM operations.

The GPIM project will also demonstrate three-axis spacecraft attitude control AF-M315E $1 \mathrm{~N}$ thrusters. The $\mathrm{BCP}-100$ vehicle momentum wheels and torque rods will be disabled for this portion of the mission. The BCP-100 platform must support safe operation of one to four $1 \mathrm{~N}$ thrusters in any combination during these demonstration maneuvers. This is part of the software enhancement described above.

The BCP-100 is an assembly of six component panels; four side panels, a baseplate and the PIP. Bus components mount to the interior side of each of these panels. The GPIM SV uses two deployed, fixed solar array wings.

The GPIM Bus build will be complete this year. The Bus component panels are will be delivered to Ball in July 2014which starts Bus mechanical integration. All Bus components are currently delivered and in the cleanroom at Ball with the exception of the solar arrays which are due in August. The Bus should be fully built and checked out by early August 2014. SV integration and test will start with the delivery of the propulsion and includes all environmental testing.

\section{GPIM Propulsion Subsystem Development Status}

The Aerojet Rocketdyne (AR) 1 N (GR-1) and 22 N (GR-22) advanced monopropellant thrusters to be employed on GPIM represent the culmination of over two decades of research, spanning the development of enabling hightemperature test and data acquisition techniques applied to testing of a number of candidate propellants, extensive evaluation and test of numerous material systems for structural components and catalysts, and thruster performance characterization from less than one up to $670 \mathrm{~N}(150 \mathrm{lbf})$ thrust in both sea-level and vacuum environments ${ }^{18}$. 

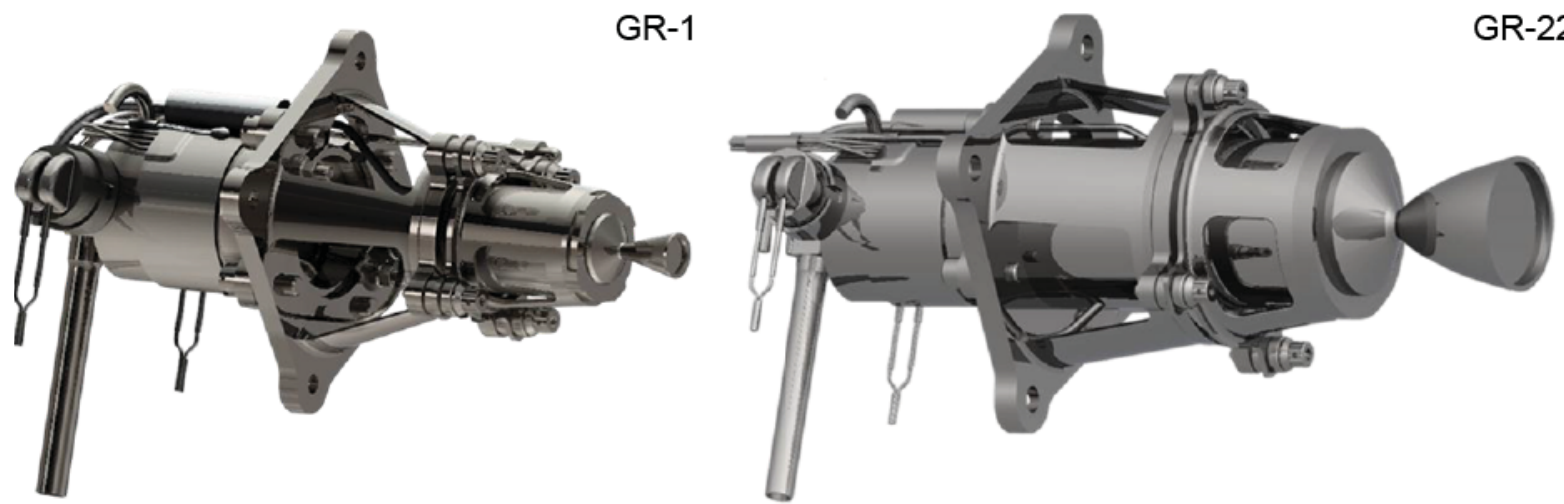

Figure 7-Aerojet GR-1 and GR-22 thrusters.

Throughout thruster developement, inherently high reaction temperatures associated with ionic liquid propellants, coupled with poorly understood ionic-liquid thruster stability dynamics, constrained both thruster life and operational duty cycle capabilities. The last several years, however, have yielded significant breakthroughs related to both materials and a fundamental understanding of the governing mechanics of ionic liquid thrusters necessary to design and fabricate robust, practical (duty-cycle-unlimited) thrusters with sufficient life capability to meet real mission needs. A key contributor to the rapid acceleration in maturation of AF M315E thruster technology seen in recent times has been the advent of AR's patent-pending LCH 240 high-temperature long-life catalyst, demonstrating sufficient endurance within the propellant's decomposition / combustion environment to extend thruster life over $15 \times$ compared to the prior state-of-the-art.

The GR-1 and GR -22 advanced monopropellant thrusters implement a common design strategy whereby the use of refractory alloys (to accommodate the flame temperature of the AF-M315E propellant) is confined to the thrust chamber, nozzle and an upper thermal isolation structure, such that much of the thruster can be fabricated with conventional alloys commonly use on hydrazine thrusters today. This hybrid approach yields significant cost and power savings compared to alternatives entailing either all-refractory or bulkier, heavily-insulated conventional alloy construction. The resulting flight thruster designs, shown side-by-side in Figure 7, comprise a series-assembled valve, injector, catalyst-containing chamber, and nozzle bearing general resemblance to conventional catalytic hydrazine thrusters of corresponding thrust classes.

In accordance with engineering best practices, the GR-1 and GR-22 thruster designs incorporate redundancy on all fracture-critical structural elements, including both portions of the mounting structure and thermal stand-off and their conjoining fasteners (as well as at the control valve-to-thruster, and thruster-to-spacecraft mechanical interfaces). As dynamic load specifications imposed for both thrusters comprise up-to-date composite spectra developed by Aerojet to ensure broad utility of new/upgraded hydrazine thruster designs, the GR-1 and GR-22 will be readily infusible into most applications likely to employ conventional monopropellants.

For launch range operations, the innate safety of the propellant, due to its low vapor toxicity, and inability to activate un-preheated obviates the conventional rationale for the use of dual seat thruster valves. Thus, single seat valves provide higher mission assurance at lower mass, power (partially offsetting added preheat power requirements), and a lower cost solution for the GPIM and future missions. Moreover, having essentially no vapor pressure, AF M315E does not self-pressurize or evaporate through small fissures such as a flaw in a valve seat. In the very unlikely event that thruster valve leakage should occur, isolation of the downstream feed system by closing the upstream system latch valve would fully prevent loss of propellant. Further, the added compactness of the GR-1 and GR-22 designs realized through the selection of single-seat valves has proven substantially facilitating in the close packaging of the GPIM demonstration system module, portending similar benefits to future ESPA-class spacecraft.

The ongoing GPIM flight thruster development effort is structured in three overlapping phases. The first phase was executed last year (July 2013), with sea-level testing of heavyweight hardware derived from parallel preliminary flight thruster design activities. This testing performed duty cycle mapping of the $22 \mathrm{~N}$ thruster over a comprehensive range to verify broad functional stability, thereafter anchoring thruster life models as operated at duty cycles and simulated feed pressure blow-down ratio closely approximating projected mission performance requirements. Guided by these test results, flight thruster designs will be completed in Phase 2 . Engineering models of both the $1 \mathrm{~N}$ and $22 \mathrm{~N}$ thrusters will be fabricated and extensively hot-fired to determine the full duty-cycle operational range and like of both thruster designs. As of the writing of this paper, only the $1 \mathrm{~N}$ had been tested to map out its' duty-cycel range. All results show that this is a very robust design with broad duty-cycle capability. The 
initial GR-1 hot fire test results will be presented in a companion paper at this conference ${ }^{30}$. In Phase 3 , flight designs will be finalized and flight (one each) qualification units fabricated. All thrusters will undergo standardized acceptance testing, comprising shock, vibration, and a hot-fire testing. On orbit, the thrusters will perform a series of maneuvers designed to both fully characterize thrust, I-bit, specific impulse, and thermal performance over a variety of duty cycles intended to encompass the full needs of near-future space applications.

\section{A. Thruster Performance}

Expected performance characteristics for the GR-1 and GR-22 are presented in Figure 8, with key operating metrics summarized in Table 1.

Table 1. Thruster Predicted Performance Summary.

\begin{tabular}{|l|l|l|}
\hline & GR-1 & GR-22 \\
\hline Thrust (N) & $0.4-1.1$ & $8-25$ \\
\hline Feed Pressure (bar) & $6.8-27.6$ & $6.8-27.6$ \\
\hline Nozzle Expansion Ratio & $100: 1$ & $50: 1$ \\
\hline Valve Power (W) & 12 & 28 \\
\hline Preheat Power (W) & 14 & 30 \\
\hline Specific Impulse (s) & 235 & 250 \\
\hline Total Impulse (N-s) & 23,000 & 74,000 \\
\hline Minimum Impulse Bit (mN-s) & 8.0 & 116 \\
\hline
\end{tabular}

\section{B. Operational Considerations}

An important operational consideration for green propellant thrusters is the amount of catalyst preheating required to prepare the thruster for operation. Both AF-M315E and hydrazine monopropellant technologies employ catalyst bed preheaters, albeit for different reasons. Whereas preheating is employed in hydrazine thrusters as a necessary means to achieve long thruster life, AF-M315E thrusters will not operate at all unless preconditioned to a minimum $290{ }^{\circ} \mathrm{C}$ catalyst activation threshold. As this preheating is substantially higher than typical hydrazine thrusters (typically $100-200{ }^{\circ} \mathrm{C}$ ), state-of-the-art AF-M315E thruster preheaters require greater heater power, which must be addressed as part of mission/system design.

\section{NASA GRC}

\section{A. Plume Modeling}

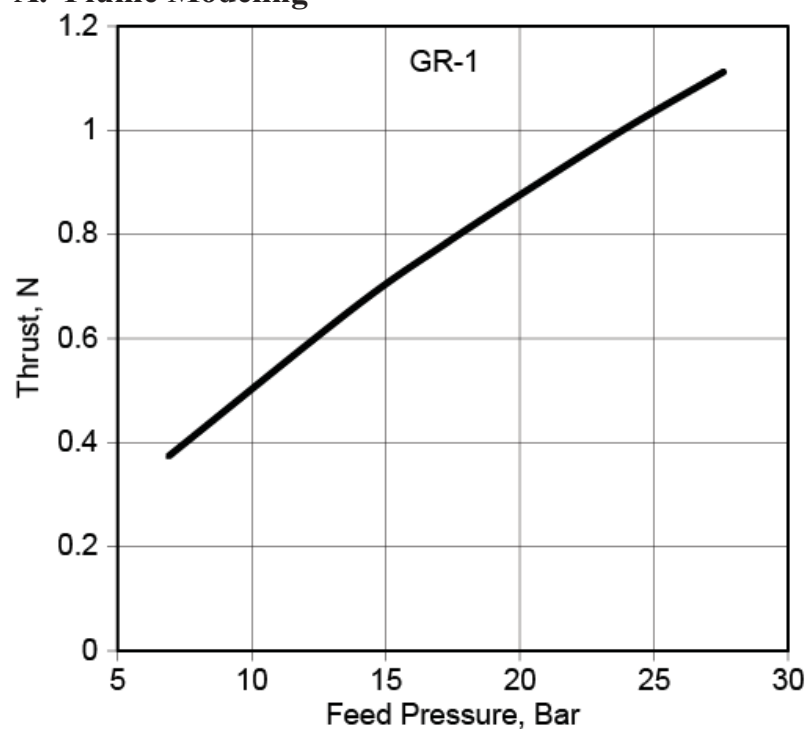

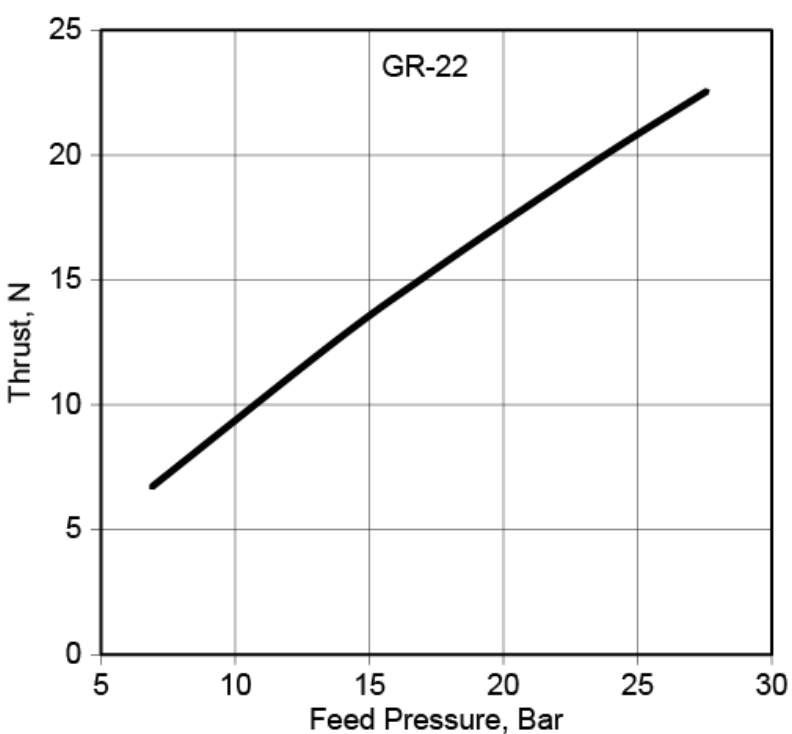

Figure 8-Aerojet Rocketdyne GR 1 and GR 22 thrust vs. feed pressure curves.

One of the risks identified for GPIM is potential contamination of sensitive areas of the spacecraft from the effluents in the plumes of the $1 \mathrm{~N}$ and $22 \mathrm{~N}$ thrusters. NASA (GRC) is modeling the plume flow fields of the these thrusters, assessing the plume impingement on the BCP-100 spacecraft, including the impact on the power generating capabilities of the solar arrays, and conducting ground-based plume measurements on an AF-M315E 
thruster to correlate the plume modeling with plume data. The initial modeling efforts and solar array plume impingement studies have been completed, with ongoing work in the experimental characterization of the plume.

Two different codes are used to examine the plume properties of the GPIM thrusters. The first used the Reacting And Multi-Phase (RAMP2) / PLume IMPingment (PLIMP) program combination. RAMP2 is an axisymmetric method-of-characteristics based code that calculates the plume flowfield ${ }^{19}$. The RAMP2 flow field can be used as an input to the PLIMP code to subsequently calculate forces, moments, pressures, heating rates, and species contamination on surfaces specified by the user ${ }^{20}$. RAMP2 and PLIMP have been used for a number of plume impingement studies including Shuttle Reaction Control System (RCS) and solid rocket boosters, Orion Service Module (SM) RCS engines, and Space Launch System (SLS) solid rocket boosters among others ${ }^{21,22,23}$.

The second model uses the Hypersonic Aerothermodynamics Particle (HAP) code. HAP is an implementation of the Direct Simulation Monte Carlo (DSMC) method ${ }^{24}$. Other DSMC implementations have been successfully used for plume flow and plume impingement studies ${ }^{25,26}$. For example, the DSMC Analysis Code (DAC) has been applied to model plumes for several different programs including plume impingement on the International Space Station, the Orion SM RCS engines, and the Altair lunar lander ascent engine among others ${ }^{27,28,29}$.

The primary findings of the modeling effort show that greater than $92 \%$ of the total plume kinetic energy is contained within a 30 degree half-angle cone of the thrust vector as shown in Figure 9. This compares with the ruleof-thumb that is used by the industry for the standard hydrazine thrusters, thus AF-M315E does not require any further restrictions on thruster placement and orientation than are applied for state of the art monopropellant thrusters. The plume impingement heating rates on the spacecraft surfaces were also calculated for the GPIM specific configuration. As shown in Figure 10, the expected heating rates from plume impingement are very low. They are at least an order of magnitude - and often much more-lower than the heating rates from thruster chamber and nozzle radiation heating or even solar irradiance at $1 \mathrm{AU}$.

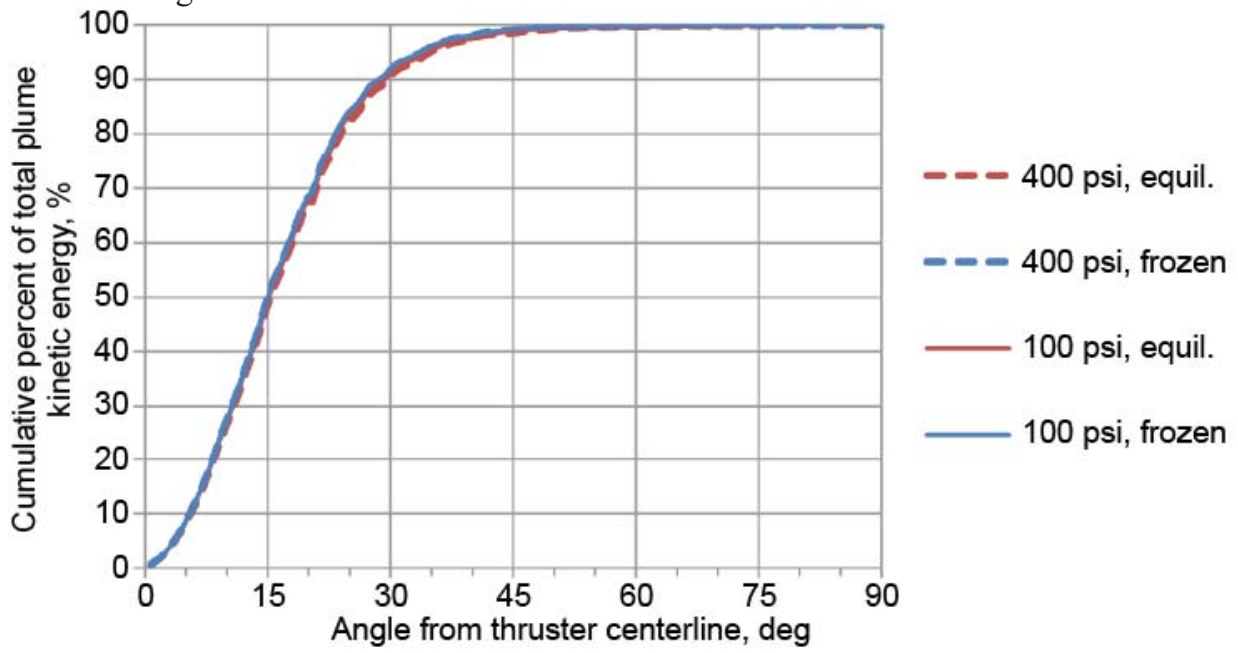

Figure 9-Cumulative percent of total plume kinetic energy for the $22 \mathrm{~N}$ thruster.

Another concern with AF-M315E propellant is the potential deposition and contamination of the its plume effluents onto sensitive spacecraft surfaces e.g., water vapor in the plume exhaust. However, modeling efforts indicate that water comprises less than $1 \%$ of the plume by mole fraction past $75^{\circ}$, and less than $0.1 \%$ beyond approximately $90^{\circ}$ from the thrust axis. This is highlighted in Figure 11. Hydrogen gas is seen to dominate the backflow region of the plume, where most spacecraft surfaces would be expected to be located. A preliminary deposition analysis has shown water vapor accumulation is not expected to be significant based on calculated surface fluxes and estimated target surface temperatures.

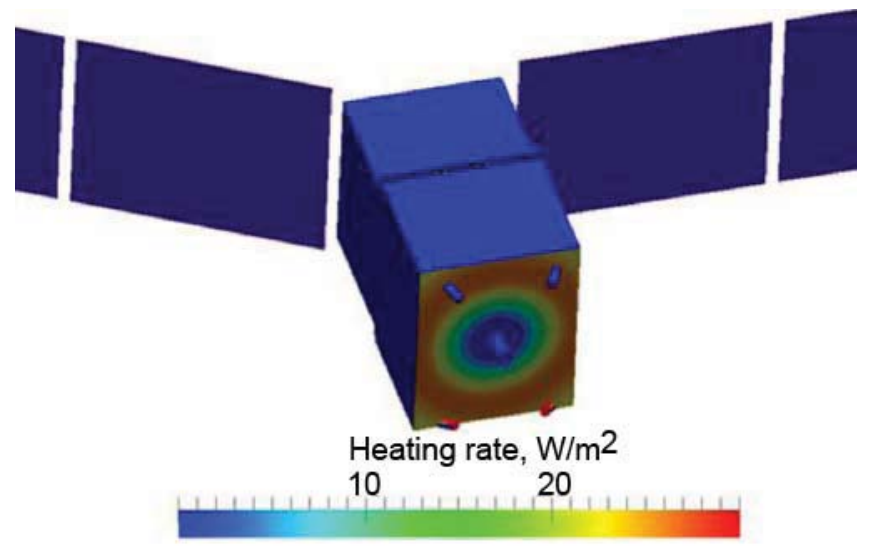

Figure 10-Heating rates calculated by RAMP2/PLIMP on the BCP-100 spacecraft surfaces from the central $22 \mathrm{~N}$ thruster firing.

11

American Institute of Aeronautics and Astronautics 
Another potential concern could be that of incomplete combustion. The combustion intermediate compounds have relatively high molar masses and it is expected these species will have a very low presence in the backflow region of the plume. A correlation between the molecular weight of a given plume species and its presence in the backflow region was noted in the modeling results.

Future work includes anchoring the models to experimentally-obtained data from a set of tests currently being conducted at NASA GRC.

Another aspect of the study carried out at NASA GRC was the computational analysis and evaluation of the effects of plume impingement on solar arrays. Thruster plume impingement can cause both chemical contamination and erosion of the solar cells as well as thermal and force loading on solar arrays. These issues can lead to a degradation in power generation capabilities

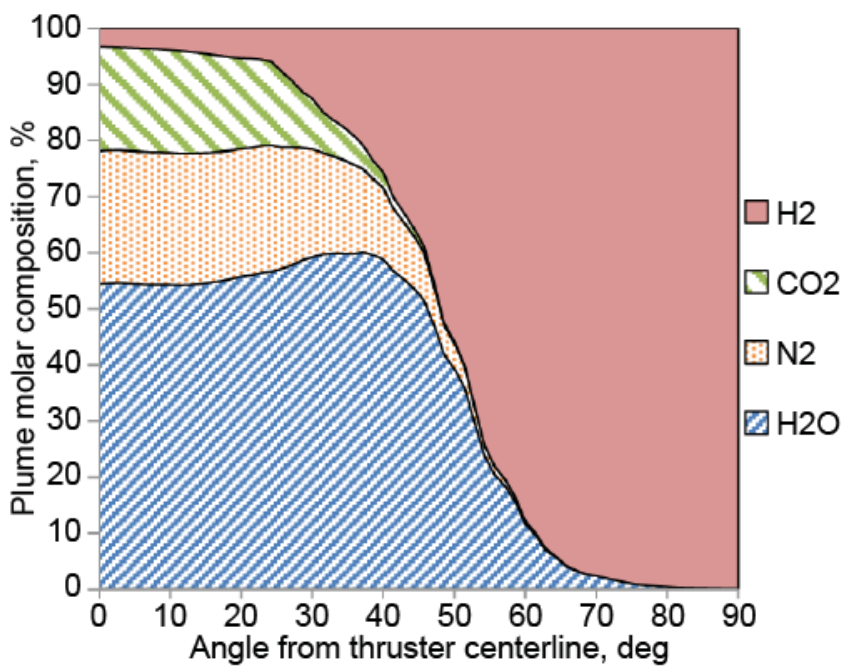

Figure 11-Plume species molar fractions assuming equilibrium flow at a $40 \mathrm{~cm}$ radius from the center of the $22 \mathrm{~N}$ thruster exit plane. through loss in optical transparency or increase in reflectivity of the solar cells' coverglasses, or overheating of the cells ${ }^{31}$.

For the GPIM spacecraft, power is generated by two non-articulating rigid panel solar array wings (SAWs). When the thrusters fire, there is a risk that their plumes may impinge upon the SAWs. The $22 \mathrm{~N}$ thruster can impinge both deployed arrays. Two $1 \mathrm{~N}$ thrusters can impinge the deployed non-canted array while the remaining two $1 \mathrm{~N}$ thrusters can impinge the deployed canted array. A graphical representation of these plumes and the impingement is shown in Figure 12.

Chemical thruster plume impingement on SAWs can lead to chemical contamination of the optically sensitive solar cells. If plume contaminant deposits onto the solar cell surface, the contamination layer will both reflect and absorb a portion of the incident solar energy, effectively preventing it from reaching the solar cell. This degrades the power generation capability of the solar cells. Generally, plume species will not accumulate on a surface unless the local
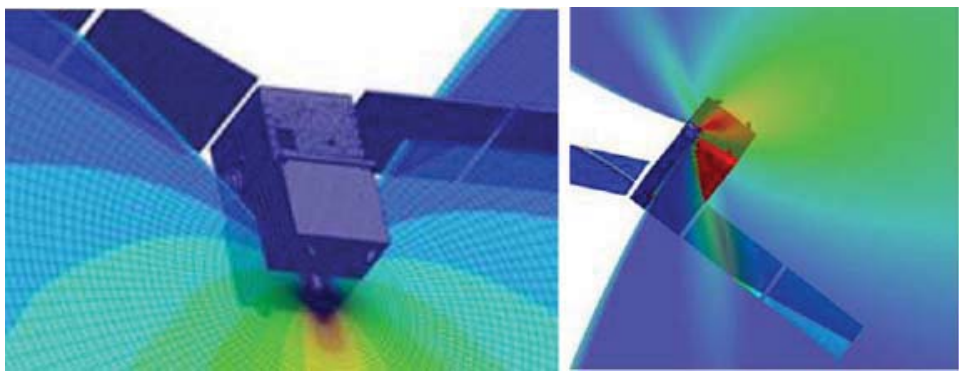

Figure 12-Graphical representation of $22 \mathrm{~N}$ thruster plume (left) and 1-N thruster plume (right)

impingement pressure is greater than the vapor pressure of the contaminant species. Vapor pressure is species and temperature-dependent.

Based on the incident plume pressures and expected temperatures of the SAWs, water is the only steady state combustion product with the potential to accumulate on the solar arrays. The results of the GPIM configuration modeling show that it is unlikely that a significant amount of plume mass will contact the solar cell side of the SAWs. All steady-state plume accumulation will be on the backside of the SAWs. The water that deposits on the SAW surface will sublime during solar insolation periods. There will be no SAW power generation degradation due to plume deposition resulting from steady state thruster operation. There is a possibility that the non-steady state plume contaminants may also exist and could alter the optical properties of the backside of the SAW. This could increase the operating temperature of the SAW and lower the solar cell efficiency. However, due to the likely plume structure and firing duration, the contaminant layers are very thin, thus the change in optical properties is expected to be negligible. As a result, there will be no SAW power generation degradation due to chemical contamination resulting from non-steady state thruster operation.

Thermal loading is also a concern; chemical thruster plume impingement can cause heat transfer between the plume and SAW resulting in thermal loading. The incident plume heat flux and the thruster firing time drive a temperature increase on the SAW. In general, as a solar cell's operating temperature increases, power output decreases. Large increases in the operating temperature of the solar cells could result in significant efficiency drops. 
Additionally, if the temperature exceeds the design limit of the SAWs there is the potential for catastrophic damage to occur that could prevent the arrays from generating power.

A model was created to assess the impact of AF-M315E thruster plume heat fluxes on GPIM's SAWs. The model takes the mass, density, and thermo-physical properties of the individual layers of the solar cell and panel into account. The model assumes the thruster plume is incident on the back (non-solar cell) side of the SAWs. The most thermally stressing analysis case was assessed. The thermal analysis results show that the temperature limit of the SAWs is not exceeded. Additionally, the thruster plume heat flux results in less than a 1 degree Celsius temperature increase on the SAWs. This modest temperature increase will cause a negligible degradation in solar cell efficiency. There will be no SAW power generation degradation due to thermal loading.

Erosion is another potential concern. During non-steady state thruster operation, droplets of uncombusted AFM315E may be present in the thruster plume. If these droplets hit the SAWs, their impacts will be similar to that of micrometeoroids and orbital debris. The main concern associated with droplet erosion is the possibility for the removal of SAW coatings, especially on the solar cells. Most solar cells are covered in an anti-reflective coating that helps prevent incident sunlight from reflecting off the cell and back into space. If some or all of this coating is removed, less solar energy will be available to the solar cells, which results in a lower power output ${ }^{30}$. Particle impingement angle affects the amount of SAW surface erosion. The analysis demonstrated that uncombusted AFM315E droplets will not be of sufficient size or prevalence to cause damage to the front or back of the solar array. There will be no SAW power generation degradation due to erosion.

Lastly, force loading of a plume on a SAW could potentially be a concern. Plume impingement induces both vibration and mechanical shock on GPIM's SAWs. If the thruster firing rate induces a vibration on the SAWs equal to either the fundamental frequency or a higher order harmonic of the fundamental frequency of the SAWs, the SAWs could be excited to high stress levels after several tens of cycles. When chemical thruster plumes impinge SAWs, the plumes apply a sudden and short-duration force to them.

Discretized individual moments were summed for the full SAW to calculate wing-level moments based on the worst case scenarios. The bending moments calculated do not exceed the GPIM SAW design limits. Although the design limits in the torsional direction have not yet been quantified, it is expected that the torsional moments will not exceed the GPIM SAW design limits, because the calculated moments are very small. Based on the available data, there will be no SAW power generation degradation due to force loading from the AF-M315E thrusters.

In order to improve the fidelity of future AF-M315E plume impingement analysis efforts, it is recommended that both the sticking fraction and optical properties of the contaminant products of AF-M315E be better quantified. Given that the GPIM SAWs are exposed to very small thruster plume mass fluxes, neither piece of data is necessary for this particular analysis - the analysis conclusions will not change. However, the data may be needed for any future analyses on vehicles that experience higher thruster plume mass fluxes on the SAWs.

Detailed results of these analyses will be presented in a dedicated future release. AF-M315E thruster plume impingement is not expected to cause power generation degradation on the GPIM SAWs; chemical contamination, thermal loading, erosion, and force loading were all shown to have minimal effect on the spacecraft.

\section{B. NASA GRC Plume Diagnostic Testing Facility}

GPIM testing at GRC will utilize two different AF-M315E $22 \mathrm{~N}$ class thrusters manufactured by AR. These thrusters use the same catalytic reactor and catalytic materials as the GPIM flight unit. The first thruster to be tested is a Laboratory Model (LM) thruster; this is essentially a heavyweight and highly instrumented thruster with a relatively small nozzle expansion ratio. For laser plume diagnostics, denser gasses emitted from this sized nozzle may yield greater diagnostic signal strength relative to the lower pressure products emitted from a larger nozzle. Thrust measurement will also be performed as part of the LM thruster firings. As of the submission of this paper, this testing is currently ongoing.

The second thruster is an Engineering Model (EM) thruster; this is essentially a flight-like thruster. This thruster will have a larger nozzle expansion ratio. Despite the lower exit pressures associated with the larger nozzle, new advancements in GRC laser diagnostics may still be able to detect valid signals. Thrust will continue to be measured. Testing with this thruster is scheduled to occur in September and October of 2014. Both thrusters will be modeled and corroborated individually to provide greater insights into plume behavior.

Testing for both thrusters will be conducted at multiple chamber pressures to simulate the blow-down operation of the flight thruster. The objective will be to collect multiple plume measurement data, at each pressure test point.

Testing will be conducted at GRC's Research Combustion Laboratory - Cell 11 (RCL-11). RCL-11 is a small rocket $(<220 \mathrm{~N})$, altitude $(36.6 \mathrm{~km})$ facility designed with optical access to incorporate the use of laser-based diagnostics. The facility uses a six-foot long, three-foot diameter cylindrical vacuum tank. The vacuum tank has four viewports, three located in a plane perpendicular to the thruster axis and the other at a 60-degree angle with the 
thruster axis. Vacuum is achieved by the use of a two-stage ejector system driven by motive air supplied from a central GRC facility. The thruster is fired horizontally into a water-cooled diffuser, which provides an additional pumping effect for the vacuum tank. RCL-11 has been used to test thrusters for up to 1 hour in duration, with the test duration limited by the thruster rather than the vacuum capability. Figure 12 shows the RCL-11 test stand with the vacuum tank in a position to allow for access to the test article.

RCL-11 was initially designed for gaseous oxygen and gaseous hydrogen propellants, but has been modified to conduct tests with heated nitrogen, ethanol, and Tridyne ${ }^{\mathrm{TM}}$ (nitrogen/hydrogen/oxygen mixtures) propellants. Independent of the GPIM program, there is an effort underway to adapt RCL-

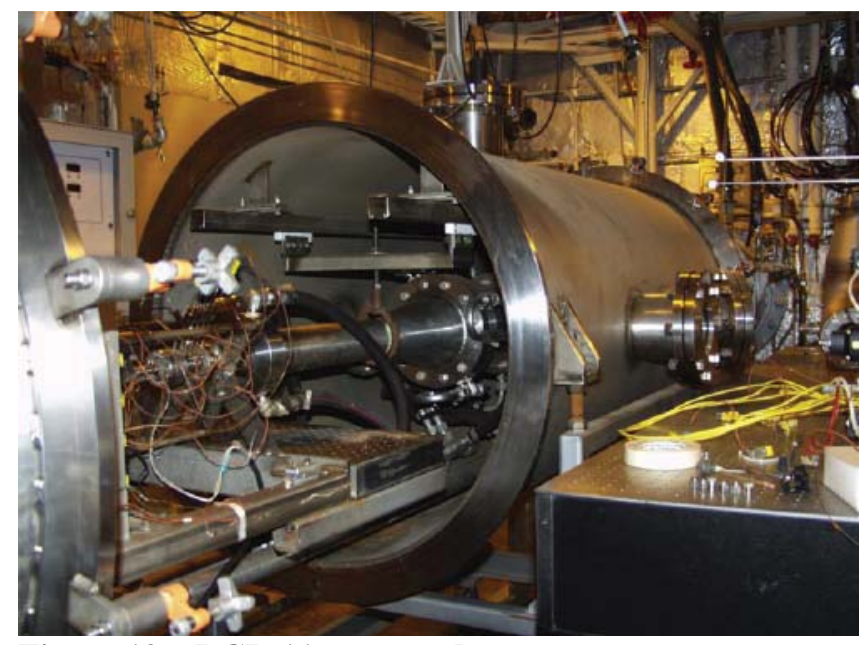

Figure 12-RCL-11 test stand.

11 to test ionic salt monopropellants, including the establishment of a temperature-controlled propellant storage facility (Figure 13). For the GPIM plume measurement testing, a dedicated feed system has been developed and installed in RCL-11. This feed system is similar to designs used by Aerojet in their testing of HAN-based monopropellant thrusters.

The facility includes a laser table adjacent the vacuum chamber for the setup of laser-based diagnostics. RCL-11 also has a dedicated laser diagnostics room behind the blast wall, with feedthroughs for optical cabling, to allow personnel to work freely during testing. There have been several test series conducted in RCL-11's history using laser-based diagnostics, primarily to investigate internal flow field and plume behavior in small rockets. For the GPIM plume measurements, the suite of diagnostics is expected to include Rayleigh spectroscopy, Raman spectroscopy, and Schlieren imaging.

Rayleigh and Raman spectroscopy both involve introducing a laser light source into the plume and detecting the scattered light, as illustrated in Figure 14. Rayleigh scattering refers to the elastic portion frequency as the excitation source. The spectrum of Rayleigh scattered light can provide information about the thermodynamic parameters of the gas. Raman scattering refers to the inelastic portion of the scattered light, that is, the shift in energy from the excitation source. Each species in the flow field scatters light at different wavelengths. The Raman scattering spectrum can be used to determine the concentration of all the species in the flow, based on its characteristic Raman scattering of photons. Temperature measurement can also be determined from the Raman spectrum. However, the Raman spectrum represents a small portion of the scattered light, resulting in a weak signal that is difficult to resolve. For the low-density region of the 50:1 area ratio GPIM thruster plume, it will be necessary to use very high power lasers and sensitive detectors.

Schlieren imaging is a well-established
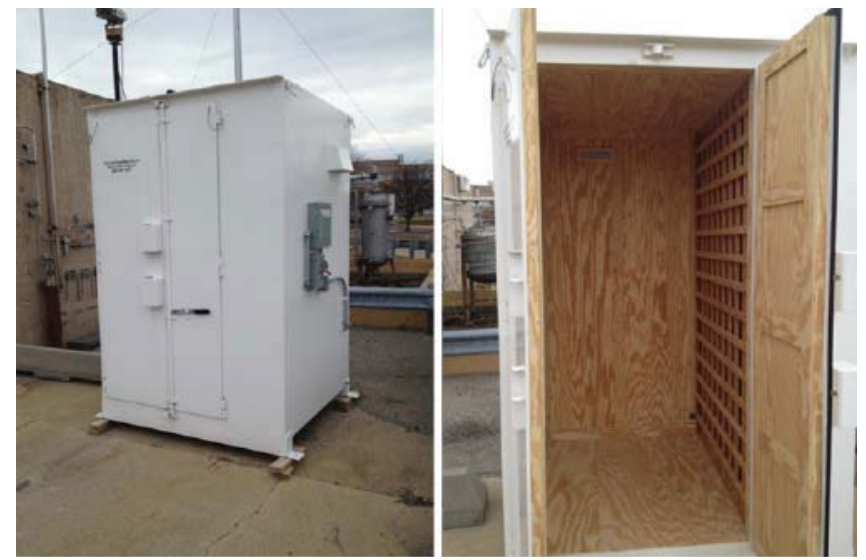

Figure 13-GRC advanced monopropellant storage locker.

of the scattered light, that is, the light scattered at the same

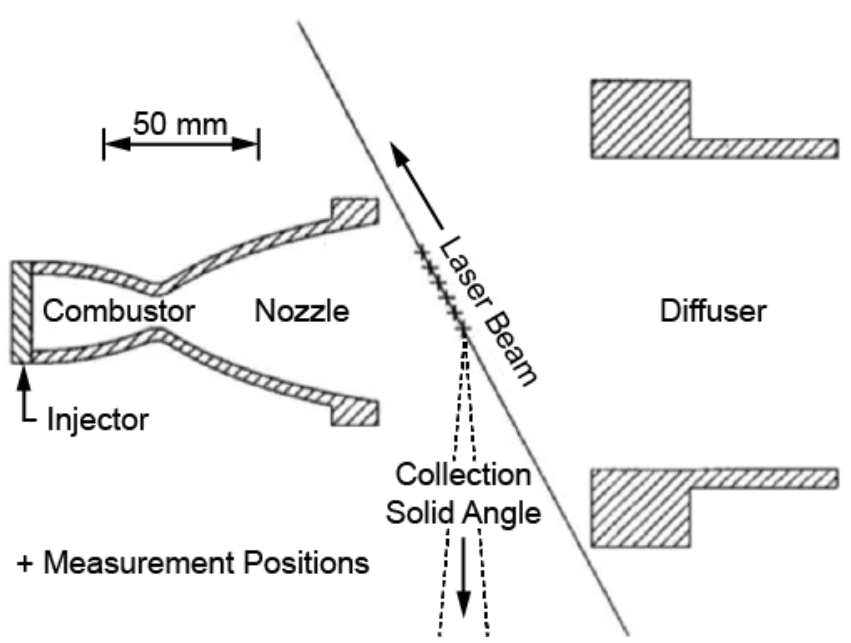

Figure 14-Illustration of plume measurement approach for Rayleigh and Raman diagnostics. 
technique used to visualize the relative density in fluids. Schlieren imaging is an inexpensive, simple diagnostic to implement, though it will only provide qualitative results. In addition to laser-based diagnostics, physical probes are being considered for plume measurements. This could include witness plates with thermocouples to measure temperatures at discrete points in the plume.

The results of the plume measurement testing will be compared to simulations developed using plume modeling from RAMP2/PLIMP and HAP models.

Testing of the laboratory model thruster began in June of 2014; this test campaign is the first NASA testing of these AF-M315E thrusters. As of the submission of this paper, initial checkouts of the Raman and Schlieren diagnostics have begun as seen in Figure 15. The results of the plume measurement testing will be compared to simulations developed using plume modeling from RAMP2/PLIMP and HAP models. Findings of this testing and comparison will be presented in a future publication.

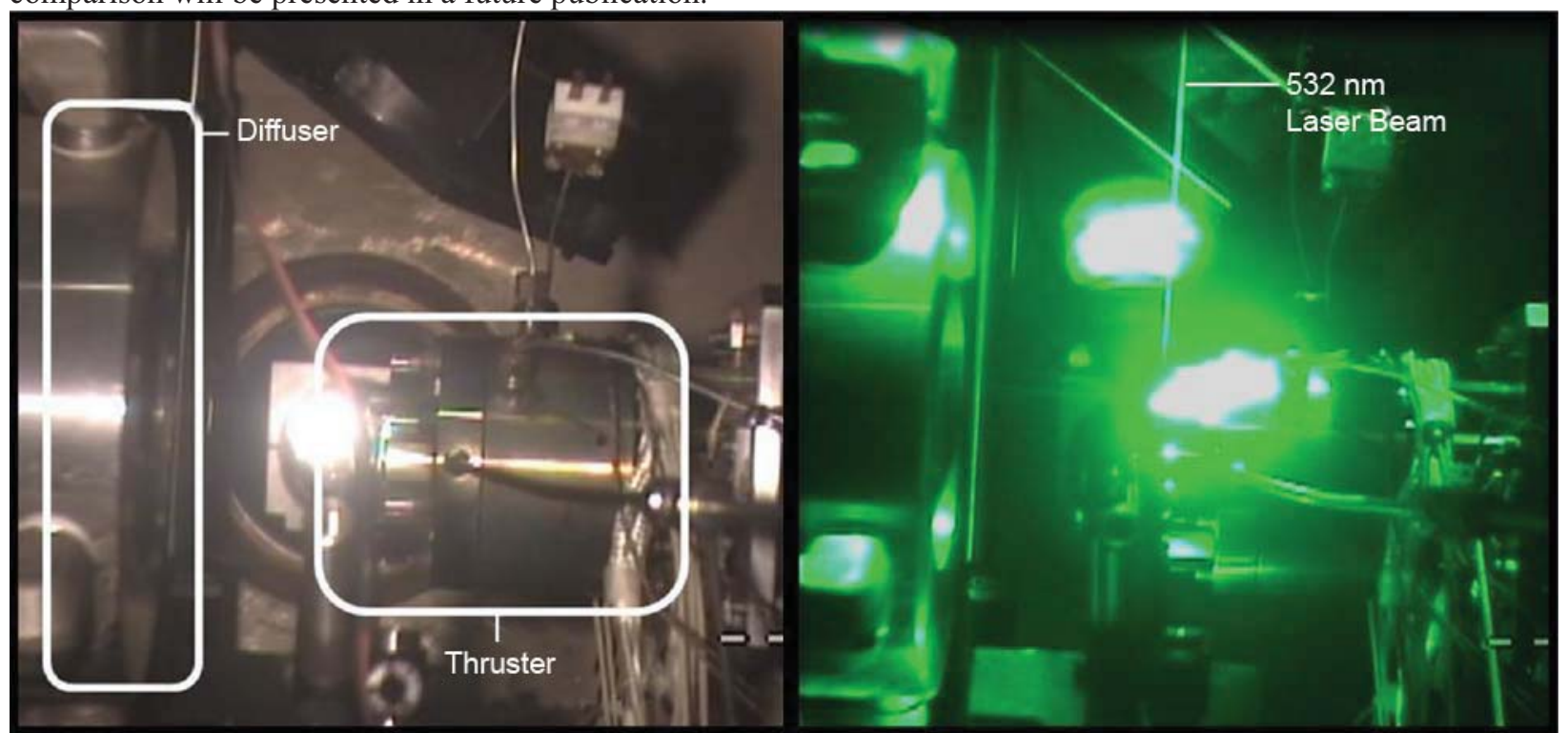

Figure 15-Testing of Laboratory Model Thruster at Altitude, Left: Thruster-Only Firing, Right: Raman Diagnostic Firing.

\section{NASA KSC}

NASA KSC is working within the GPIM project in several areas, mostly related to the infusion objectives of the mission. These tasks include developing the capability to store, transfer, and otherwise handle AF-M315E on KSC and material characterization of stressed titanium in the presence of AF-M315 to allow for tank fracture mechanics analysis. These tasks will lower the learning curve for the processing of future payloads using AF-M315E at KSC and Cape Canaveral Air Force Station.

In addition to the green propellant focused activities, KSC performed GPIM mission relevant environmental testing of the IMLI that will be flown as a technology demonstration. This testing included both vibration and thermal balance characterization.

\section{A. Propellant Handling}

KSC routinely handles storable propellants, so the capability for storing hazardous fluids is not new. As AFM315 is a class 1.3 explosive when not in its shipping container and a 1.4 explosive when in its shipping container, it must be handled by personnel with appropriate explosives handling training, and stored in a proper facility. Such facilities exist at KSC and CCAFS, with the current plan being to store the small quantities of propellant currently needed at the Ordinance Storage Facility (OSF) in the Launch Complex-39 area.

Similarly, KSC has chemical laboratories set up to perform assays of hydrazine. These laboratories also contain most of the equipment to perform the assay of AF-M315E however, due to the different hazards of the two fluids, the procedures and protective equipment will be different. KSC is working with the AFRL to develop the procedures for assay and the safety data sheets required for processing this propellant at KSC.

In order to load the AF-M315E onto a spacecraft, a ground-based loading cart is required. While the AFRL is designing the cart for GPIM, KSC is providing input into the design. Additionally, KSC engineers are tasked to look 
at a wider array of loading options to help lay the ground work for future loading carts and ground equipment. One of the main issues facing this task is the lack of understanding of how many metals react with the propellant and how long it can be stored in such containers.

\section{B. Fracture Mechanics Testing}

A standard analysis that is done for every spacecraft launched under the auspices of the Air Force Range Safety is a fracture mechanics analysis that shows that the tank containing hazardous/pressurized propellant will not fail while on the launch pad, endangering technicians that may be working around the spacecraft. Additionally, the analysis is required to show that the tank will survive the life of the mission in a pressurized state with the propellant loaded. The testing that formed the basis for the analysis for hydrazine and nitrogen tetroxide in conjunction with Titanium 6Al-4V tanks were performed in the late 1960s and early $1970 \mathrm{~s}^{32,33,34}$. These test programs were designed to allow all future missions with either propellant and Ti-6Al-4V tanks to be properly designed. Thus all subsequent spacecraft have used those test results to design their spacecraft and perform the analysis required by the range. GPIM is retaining the design features of a traditional Ti-6Al-4V, elastomeric diaphragm storable propellant tank. However, the current material properties database does not address the impact of this new propellant and a material characterization is required. The Material Science Laboratory at KSC is preparing to perform such testing on the propellant/tank material combination to support GRC's NASGRO analysis for the mission. Additionally, KSC is interested in understanding the behavior of more traditional GSE construction materials when in contact with AF$\mathrm{M} 315 \mathrm{E}$ and is considering performing other testing with those materials for better characterization of the effects.

\section{Integrated Multi-Layer Insulation}

IMLI is an advanced multilayer insulation system developed by Quest Product Development (now spun off into Quest Thermal Group) and Ball Aerospace in partial cooperation with NASA through the Small Business Innovative Research (SBIR) program with Phase I, II, and III funding (Figure 16) ${ }^{35,36}$. Instead of using a netting spacer between the reflectors of the IMLI, discrete posts are used to support the blankets and keep them from touching one another. This spacing minimizes conduction heat transfer between layers, eliminates performance uncertainty due to layer density and can be accurately modeled using standard network modeling tools such as SINDA. This allows for a reduction in heat load per layer of insulation.

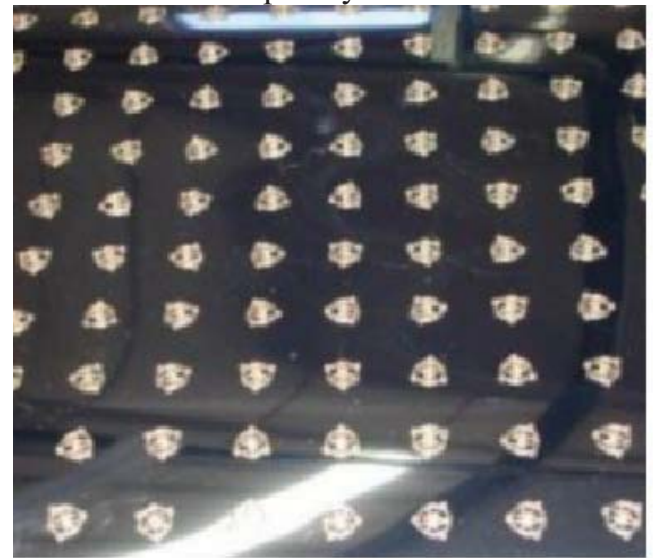

IMLI Layer with Spacers

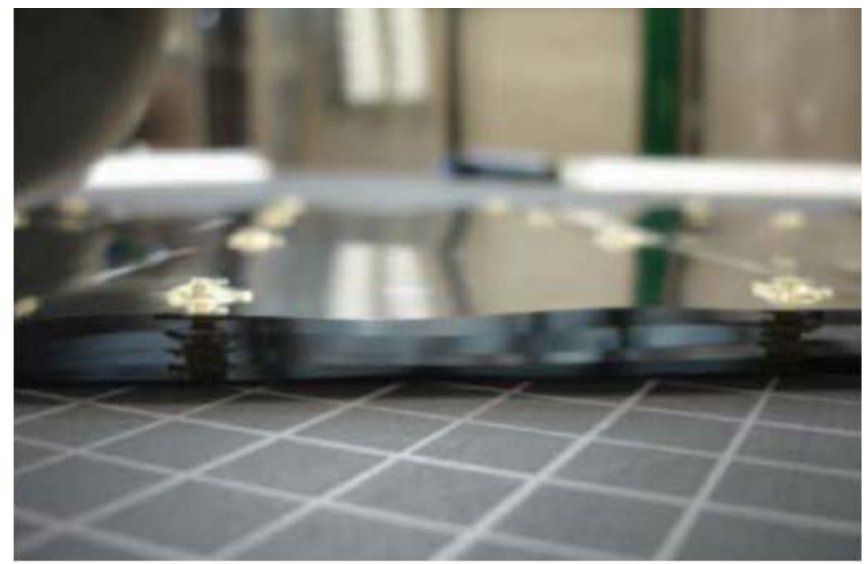

IMLI Layup

Figure 16-IMLI sheet mounted spacers and assembly. The Ball patented IMLI provides advanced, repeatable thermal insulation for spacecraft applications and will be matured to TRL 9 as part of the GPIM payload.

It was realized that the GPIM mission would be ideal for demonstrating the flight worthiness of IMLI. However, there were several residual risks that needed addressing. In order to buy down a portion of the remaining risk of launching IMLI on the GPIM spacecraft, NASA Self-Supporting Multilayer Insulation (SS-MLI) project agreed to fund several small tests at the Kennedy Space Center's Cryogenic Test Laboratory to help to flight qualify IMLI. Two main risks were identified that needed to be proven out: material compatibility at the expected flight temperatures and survival of the vibration loads expected during the launch of the GPIM spacecraft.

A thermal model has already been developed by the GPIM project at Ball Aerospace. The maximum and minimum temperatures predicted on the outer layer of the blanket are $83 \mathrm{~K}\left(-190{ }^{\circ} \mathrm{C}\right)$ and $360 \mathrm{~K}\left(87{ }^{\circ} \mathrm{C}\right)$ respectively. The IMLI materials are all rated for continuous service at the temperatures in excess of $130^{\circ} \mathrm{C}$, which is much higher than the maximum temperature predicted for the GPIM mission. However, since no IMLI have ever 
been exposed to the maximum temperature, it was agreed to complete a thermal survivability test of an IMLI blanket.

In order to demonstrate that the IMLI coupons can survive the vibration environments of launch, sinusoidal and random vibration tests are required. While IMLI has been previously tested for both acoustics and vibration ${ }^{37}$, the specific geometry of GPIM required that the IMLI only be supported at the two ends of the 16 inch wide blanket. Thus the test configuration needed to be geometrically correct.

\section{Thermal Testing}

Testing was performed using the insulation test instrument Cryostat100 at Kennedy Space Center's Cryogenics Test Laboratory as shown in Figure $17^{38}$. A five layer insulation blanket was bought from Quest Thermal Products through the SS-MLI project for Cryostat-100 testing to help to prove the thermal performance of the blankets prior to installation onto the Reduced Boil-off test.

Pre-Survival thermal testing of the coupon showed a heat flux of 1.78 $\mathrm{W} / \mathrm{m}^{2}$ with a cold boundary temperature of $78 \mathrm{~K}$ and warm boundary temperature of $293 \mathrm{~K}$. The results of the high temperature thermal survival test showed that the external temperature exceeded the required temperature of $360 \mathrm{~K}$ by several degrees and also lasted much longer than required. Thermocouples T11, T12, and T13 were placed on the outer layer of the insulation blanket and each was reading a temperature of above $360 \mathrm{~K}$ for over 2.3 hours, with $\mathrm{T} 12$ at such temperatures for 3.3 hours. The full temperature profile of the test is shown in Figure 18. The maximum temperature seen on the insulation was $376 \mathrm{~K}$ and the maximum temperature of the vacuum chamber wall was $394 \mathrm{~K}$.

3. Vibration Testing

The IMLI system was tested to meet the minimum structural



Figure 17-NASA KSC Cryostat100.

requirements necessary to ensure survivability during flight (Figure 19). Vibration testing occurred in all three axes with a sine sweep followed by a random vibration and a second sine sweep. The second sine sweep is intended to detect any damage from the random vibration testing.

The random vibration was the maximum predicted environment $+3 \mathrm{~dB}$ with one minute duration as is typical for flight payloads. The sine sweep had a $0.1 \mathrm{~g}$ amplitude in the Z-direction, and $0.25 \mathrm{~g}$ amplitude in the X and Ydirections. The amplitude increase in the $\mathrm{X}$ and $\mathrm{Y}$-directions was due to facility limitations, where the shaker table controller could not maintain a sine sweep above approximately $1,600 \mathrm{~Hz}$ at $0.1 \mathrm{~g}$. Increasing to $0.25 \mathrm{~g}$ allowed the controller to reach $2,000 \mathrm{~Hz}$. The sine sweep progressed at 4 octaves a minute, with three sweeps up and three sweeps back down for a total of six sweeps.

The IMLI was attached to two aluminum 1.5" box flanges with 1" wide Velcro (flanges having the hook side) along the entire 11.25 " width of the frame on each side. Two tear-drop accelerometers were attached to the top side of the IMLI. The first was placed centered, with the second placed 1" offcenter. The tear-drop accelerometers were attached with a minimal amount of bees wax.

The results shown in Figure 20 for the $\mathrm{Z}$ axis are typical of all three axis. The peaks in the curve indicate natural frequencies. There were no observed effects of the vibration testing observed either during the testing or during post test inspection of the blanket.

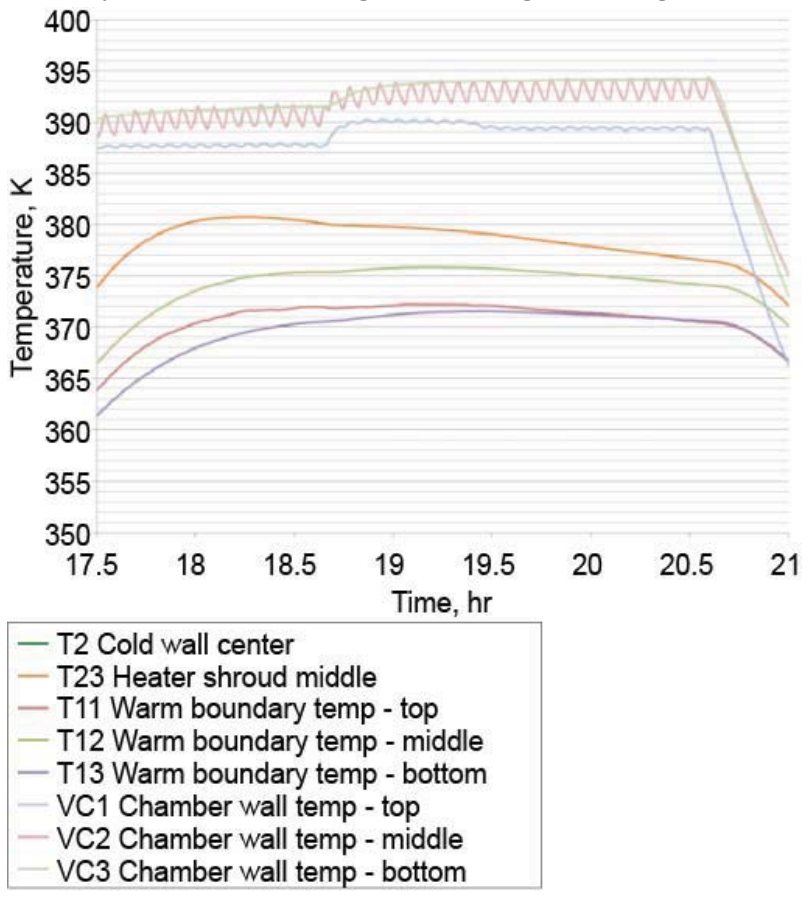

Figure 18-Thermal Survival test data.

American Institute of Aeronautics and Astronautics 


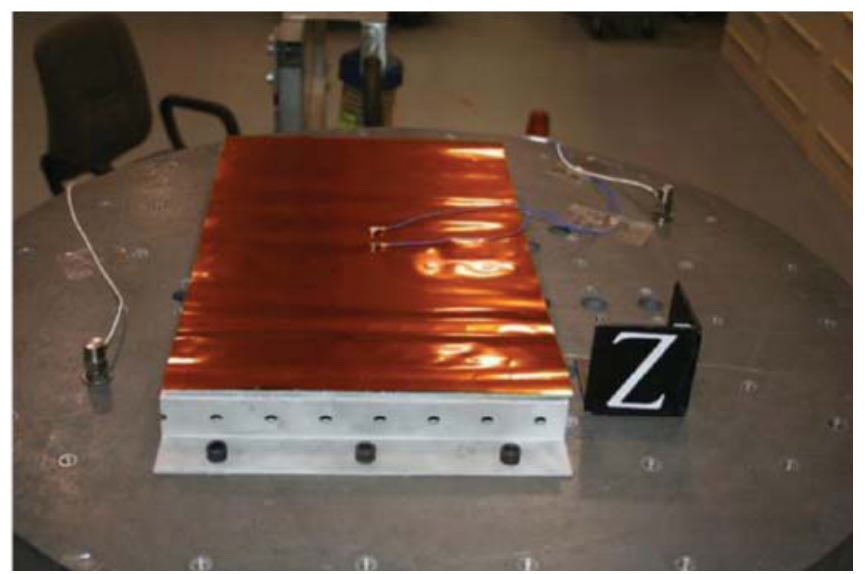

Figure 19-IMLI under vibration testing to GPIM environmental requirements.

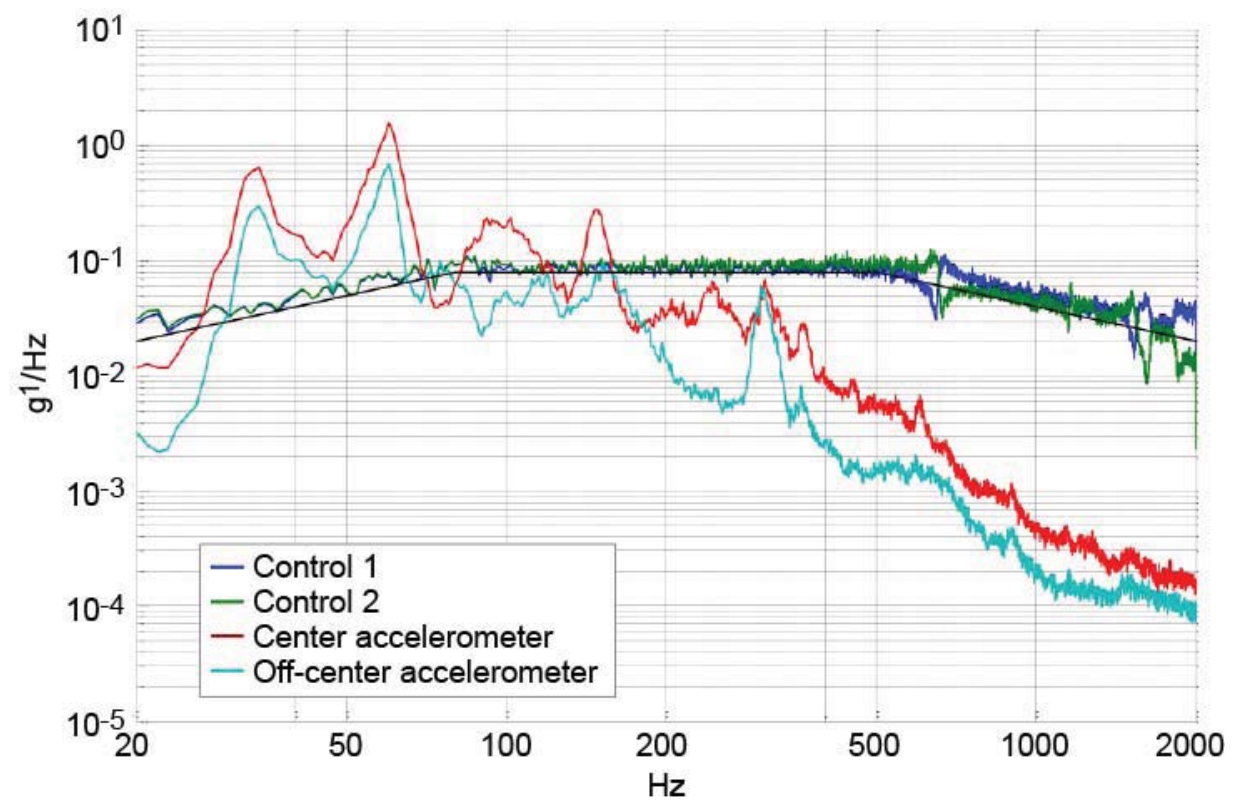

Figure 20-Vibration Survival test data.

\section{VIIII. Flight Demonstration Activities}

The GPIM on-orbit mission concept of operations consists of a series of ADCS demonstrations interspersed with $\Delta \mathrm{V}$ maneuvers. The first phase of propulsion operations consists of checkout and commissioning after the SV is checked out and operational as presented in Figure 21. These commissioning and checkout operations occur at 720 $\mathrm{km}$, starting with propulsion subsystem electrical checkout and propellant line hardening. These activities are followed by individual $1 \mathrm{~N}$ thruster checkout and initial $1 \mathrm{~N}$ thruster operations. Initial ADCS-type performance data is collected prior to $22 \mathrm{~N}$ thruster checkout to ensure the availability of a complete set of $1 \mathrm{~N}$ thruster characterization data prior to $22 \mathrm{~N}$ thruster operations. Payload commissioning is closed with $22 \mathrm{~N}$ thruster checkout and initial $22 \mathrm{~N}$ thruster operations.

After commissioning, a series of functional tests will be performed to verify operation of the propulsion subsystem, and a verification of the flight software to control the SV in primary divert operational mode. After this verification is complete, the first maneuver will be to lower the GPIM SV to less than $625 \mathrm{~km}$, putting the spacecraft at the altitude required for reentry within 25 years.

Once this orbit is established, a series of tests will occur to characterize the performance and repeatability of $1 \mathrm{~N}$ thrusters. The first tests include a series of I-bit measurements at $1 \mathrm{~Hz}$ on each $1 \mathrm{~N}$ thruster with different thruster on times $(50 \mathrm{~ms}, 200 \mathrm{~ms})$. The I-bit characterizations will be followed by several ADCS pointing control demonstrations using the $1 \mathrm{~N}$ thrusters: hold the SV orientation to within $\pm 3^{\circ}$ for an orbit or more; detumble the SV 
after inducing known body rates along each axis; control vehicle along each axis and desat wheels; and hold the SV orientation to within $\pm 0.5^{\circ}$ for an orbit or more. Demonstrations using the $1 \mathrm{~N}$ thrusters are closed out by conducting a 3 minute $\Delta \mathrm{V}$ maneuver using $1 \mathrm{~N}$ thrusters only.

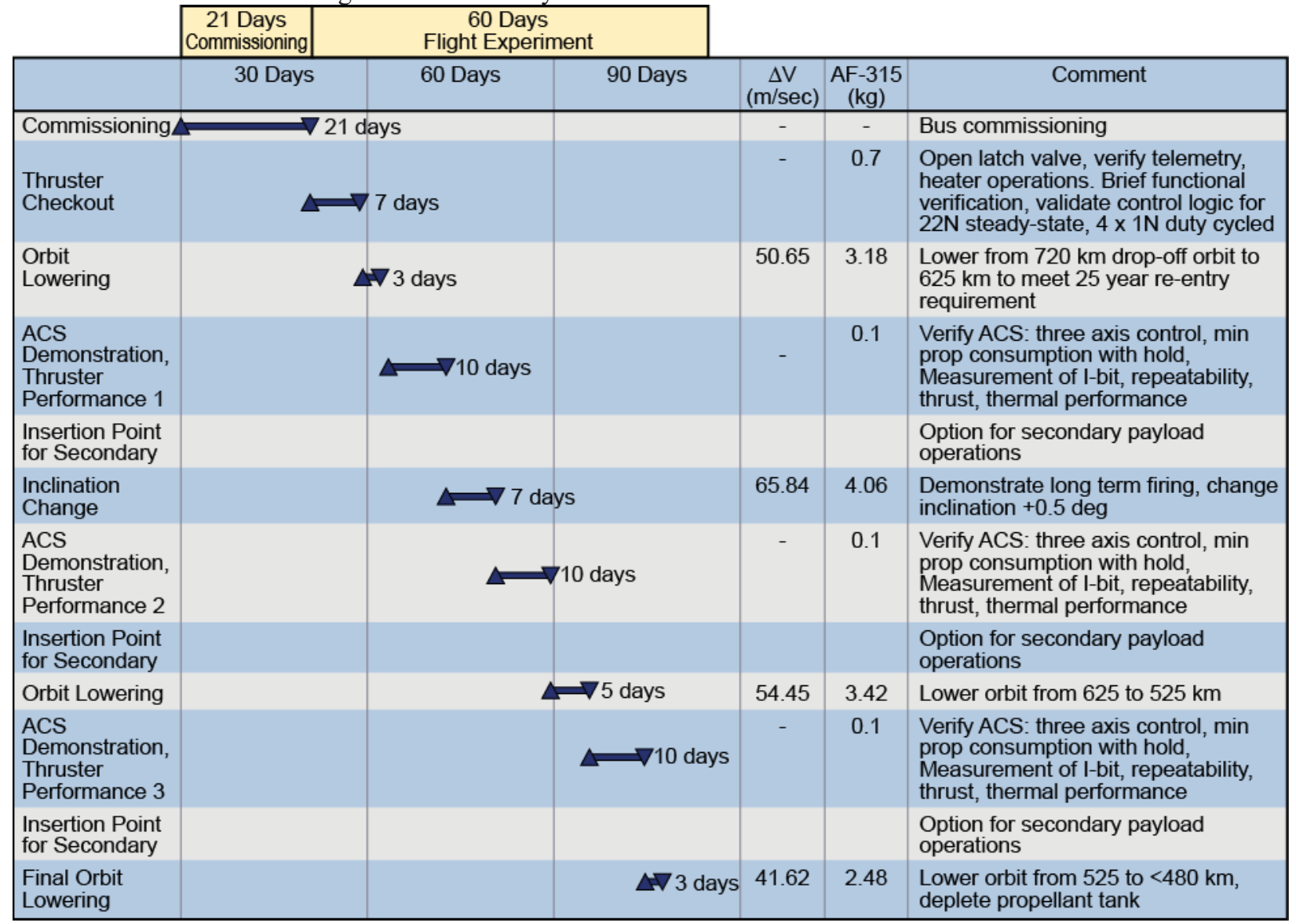

Figure 21-GPIM on-orbit operational concept. GPIM flight operations evaluates the performance an AFM315E based propulsion subsystem.

After $1 \mathrm{~N}$ thruster performance and repeatability testing are complete, another $\Delta \mathrm{V}$ maneuver will be conducted using the $22 \mathrm{~N}$ thruster controlled by off-pulsing the $1 \mathrm{~N}$ thrusters. The GPIM SV inclination is increased by $+0.5^{\circ}$ to $24.5^{\circ}$. The altitude remains at $625 \mathrm{~km}$.

After the inclination increase, the performance characterization of the $1 \mathrm{~N}$ thrusters, as described above, is repeated. Then another $\Delta \mathrm{V}$ maneuver is conducted to reduce to the orbital altitude to $525 \mathrm{~km}$ to demonstrate further $\Delta \mathrm{V}$ capability. This maneuver is followed by a repeat of the $1 \mathrm{~N}$ thruster performance and repeatability testing. A final $\Delta \mathrm{V}$ maneuver is conducted to reduce to the orbital altitude to $\leq 500 \mathrm{~km}$. A final series of $1 \mathrm{~N}$ thruster characterizations are conducted. Completion of the mission occurs with spacecraft decommissioning prior to reentry.

By conducting this series of $1 \mathrm{~N}$ thruster characterizations and $\Delta \mathrm{V}$ maneuvers, GPIM demonstrates thruster behaviors over the complete blowdown range. The series of $1 \mathrm{~N}$ thruster characterization tests result in an average of 8300 pulses per $1 \mathrm{~N}$ thruster. Due to expected mechanical and thrust vector misalignments, at least one thruster is expected to show well in excess of 10,000 pulses. Initial analyses for $22 \mathrm{~N}$ thruster operations are being done conservatively to ensure control of the GPIM SV is maintained. Initial analyses show 3700 pulses accumulated on the $22 \mathrm{~N}$ thruster since it is operated at a $50 \%$ duty cycle during $\Delta \mathrm{V}$ maneuvers $(500 \mathrm{~ms}$ on $/ 500 \mathrm{~ms}$ off). Once the $\mathrm{SV}$ is on-orbit and the $1 \mathrm{~N}$ and $22 \mathrm{~N}$ thrusters are calibrated, continuous $22 \mathrm{~N}$ thruster operations are anticipated enabling demonstration of $22 \mathrm{~N}$ thruster operations in the mode most often used for operational systems.

\section{Concluding Remarks}

The GPIM project is an industry, NASA, and DoD team consisting of Ball Aerospace, Aerojet, NASA GRC, NASA KSC, NASA MSFC, AFRL, and SMC. This project will develop, qualify, integrate, and fly an ESPA-class propulsion subsystem using AF-M315E green propellant. Two classes of thrusters will be demonstrated, $1 \mathrm{~N}$ and 22 
N. The propulsion subsystem will be provided by Aerojet; the BCP-100 bus, space vehicle AI\&T activities, launch support, and flight data review will be provided / performed by Ball Aerospace. NASA GRC is developing and validating models of the thruster plumes, including ground testing of a laboratory model of the $22 \mathrm{~N}$ thruster. AFRL will provide the propellant and the propellant loading cart for the mission. NASA KSC is providing support for AFM315E propellant handling and loading, IMLI testing to support the flight experiment, and materials testing to facilitate fracture mechanics analysis that will be performed by NASA GRC for the propellant tank. NASA MSFC is providing engineering and contract management oversight. At the completion of 60 days of on-orbit demonstration testing, sufficient data will be developed to allow for infusion of AF-M315E as a hydrazine replacement for spacecraft attitude control and primary propulsion. A successful demonstration will bring this technology to TRL 9. Subsequent infusion of this green propellant based thrusters are expected to result in lower cost, increased safety and higher performance as compare to thrusters of this class currently used by the Spacecraft industry.

\section{Acknowledgments}

The Ball Aerospace GPIM TDM project team would like to thank NASA Marshall Space Flight Center for their support of this work under contract number NNM12AA79C. The authors are grateful for the support.

The authors would like to thank AFRL, Aerospace Systems Directorate, Edwards AFB, for their efforts in support of the work described in this paper.

\section{References}

${ }^{1}$ McLean, C., et al,“Green Propellant Infusion Mission Program Overview and Status”, 2014 IEEE Aerospace Conference, March 2014, Big Sky, MT

C. McLean et al., "Green Propulsion Infusion Mission, Program Construct, and Mission Objectives," 49th AIAA/ASME/SAE/ASEE Joint Propulsion Conference, San Jose, CA, July 2013.

${ }^{2}$ C. McLean, R. Spores, and J. Sheehy, "Green Propulsion Infusion Mission, Program Construct, and Mission Objectives," Commercial and Government Responsive Access to Space Technology Exchange (CRASTE) Conference, Bellevue, WA, 24-27 June, 2011.

${ }^{3}$ C. H. McLean, R. Spores, and J. Sheehy, "Green Propellant Infusion Mission, Program Construct, and Mission Objectives," 60th JANNAF Propulsion Meeting, Colorado Springs, CO, May 2013.

${ }^{4}$ T. W. Hawkins, A. J. Brand, M. B. McKay, and M. Tinnirello, "Reduced Toxicity, High Performance Monopropellant at the U.S. Air Force Research Laboratory,” Air Force Research Laboratory, 10 E. Saturn Blvd, Edwards AFB, CA 93524.

"Monopropellant Unit 36 - AF-M315E," CPIA M4 - Liquid Propellants and Fuels, The Johns Hopkins University, Chemical Propulsion Information Analysis Center (CPIAC), 10630 Little Patuxent Parkway, Suite 202, Columbia, MD 210443200 .

${ }^{6}$ J. D. Moore, P. Gumulak, A. P. Zuttarelli, B. D. Kidd, and E. Savrun, "Experimental Characterization of Advanced, High Temperature Catalyst for Ionic-based-Liquid Monopropellants" JANNAF 8th MSS / 6th LPS / 5th SPS Joint Meeting, 5-9 December 2011, The Johns Hopkins University, Chemical Propulsion Information Analysis Center, 10630 Little Patuxent Parkway, Suite 202, Columbia, MD 21044-3200.

${ }^{7}$ S. R. Saretto, J. J. Polaha, R. B. Masse, R. Spores, J. Singleton, and A. P. Zuttarelli, Liquid Engine Alternative Propellant Development Program (LEAP DP) Brassboard Test Campaign: Thruster Performance Characterization, 57th JANNAF Joint Propulsion Meeting, Colorado Springs, CO, May 2010.

${ }^{8}$ J. Polaha, R. B. Masse, S. R. Saretto, R. Spores, J. Singleton, and A. P. Zuttarelli, Liquid Engine Alternative Propellant Development Program (LEAP DP) Brassboard Test Campaign: Materials and Catalyst Performance, 57th JANNAF Joint Propulsion Meeting, Colorado Springs, CO, May 2010.

${ }^{9}$ W. Deininger et al., "Implementation of the Green Propellant Infusion Mission (GPIM) on a Ball Aerospace BCP-100 Spacecraft Bus," 49th AIAA/ASME/SAE/ASEE Joint Propulsion Conference, San Jose, CA, July 2013.

${ }^{10}$ Deininger, W. D., et al., "Description of the Green Propellant Infusion Mission," IEEE 2014 Aerospace Conference, Big Sky, MT, USA, 1-8 March 2014.

${ }^{11}$ B. Reed, M. Deans, J. Yim, K. Bury, G. Williams, C. McLean, and J. Sheehy, "Green Propellant Infusion Mission Plume Impingement Analysis Approach,” 60th JANNAF Propulsion Meeting, Colorado Springs, CO, May 2013.

${ }^{12}$ J. T. Yim, B. D. Reed, and C. H. McLean, "Green Propellant Infusion Mission Plume Impingement Analysis," 49th AIAA/ASME/SAE/ASEE Joint Propulsion Conference, San Jose, CA, July 2013.

${ }^{13}$ B. Greene, D. J. Mast, and M. B. McClure, “AF-M315E Ionic Monopropellant Non-Combustion Product Characterization," 59th JANNAF Propulsion and 41st Structures and Mechanical Behavior Meetings, San Antonio, TX, May 2012.

${ }^{14}$ C. Badgett, N. Merski, M. Hurley, P. Jaffe, H. Walden, A. Lopez, M. Pierce, and D. Kaufman, "STP-SIV and ORS ISET Spacecraft-to-Payload Interface Standards," IEEEAC paper \#1691, Ver. 1, IEEE Aerospace Conference, Big Sky, MT, USA 2009.

${ }^{15}$ N. Merski, K. Reese, M. Pierce, and D. Kaufman, "Space Test Program Standard Interface Vehicle Lessons Learned: An Interim Assessment of Government and Contractor Progress Towards Development of a Standard, Affordable ESPA-Class Spacecraft Product Line," IEEEAC paper \#1230, Ver. 4, IEEE Aerospace Conference, Big Sky, MT, USA 2010. 
${ }^{16}$ K. Reese, D. Acton, V. Moler, B. Landin, and J. Deppen, "Rapid Accommodation of Payloads on the Standard Interface Vehicle through Use of a Standard Payload Interface," 2.0204, IEEE Aerospace Conference, Big Sky, MT, USA, 2013.

${ }_{17}^{17}$ “Space Test Program-Standard Interface Vehicle (STP-SIV) Payload Users Guide," Revision D, 2013.

${ }^{18}$ R. Spores, R. Masse, S. Kimbrel, C. McLean, "Green Propellant Infusion Mission Propulsion System Development," 49th AIAA/ASME/SAE/ASEE Joint Propulsion Conference, San Jose, CA, July 2013.

${ }^{19}$ S. D. Smith, "High Altitude Chemically Reacting Gas Particle Mixtures," NASA CR-171826, August 1984.

${ }^{20}$ R. L. Bender, R. E. Somers, M. J. Prendergast, J. P. Clayton, and S. D. Smith, "1991 Version of the Plume Impingement Computer Program," NASA CR-194192, October 1991.

${ }^{21}$ W. C. Rochelle, J. R. Hughes, J. DeVenezia, S. A. Bouslog, K. S. Leahy, and S. M. Fitzgerald, "Plume Impingement Heating to International Space Station (ISS)," 30th AIAA Thermophysics Conference, San Diego, CA, AIAA-95-2132, June 1995.

${ }^{22}$ X. J. Wang, F. E. Lumpkin, F. Gati, J. R. Yuko, and B. J. Motil, "Orion Service Module Reaction Control System Plume Impingement Analysis Using PLIMP/RAMP2," 47th AIAA Aerospace Sciences Meeting and Exhibit, AIAA-2009-0834, January 2009.

${ }^{23}$ M. Mehta, B. Williams, G. C. Putnam, and S. D. Smith, "Numerical Modeling of Solid Rocket Motor Plumes," 2012 Thermal and Fluids Workshop, Pasadena, CA, August 2012.

${ }^{24}$ J. M. Burt, E. Josyula, and I. D. Boyd, "Novel Cartesian Implementation of the Direct Simulation Monte Carlo Method," Journal of Thermophysics and Heat Transfer, Vol. 26, No. 2, pp. 258-270, 2012.

${ }^{25}$ A. D. Ketsdever, T. C. Lilly, S. F. Gimelshein, and A. A. Alexeenko, "Experimental and Numerical Study of Nozzle Plume Impingement on Spacecraft Surfaces," 24th International Symposium on Rarefied Gas Dynamics, Bari, Italy, AIP Conf. Proc. Vol. 762, pp. 367-372, July 2004.

${ }^{26}$ K. C. Kannenberg and I. D. Boyd, "Three-Dimensional Monte Carlo Simulations of Plume Impingement," Journal of Thermophysics and Heat Transfer, Vol. 13, No. 2, pp. 226-235, 1999.

${ }^{27}$ F. E. Lumpkin, III, J. Marichalar, B. D Stewart, "High Fidelity Simulations of Plume Impingement to the International Space Station," 33rd JANNAF Exhaust Plume and Signatures Subcommittee Meeting, Monterey, CA, December 2012.

${ }^{28}$ A. Prisbell, J. Marichalar, F. Lumpkin, and G. LeBeau, "Analysis of Plume Impingement Effects from Orion Crew Service Module Dual Reaction Control System Engine Firings," 27th International Symposium on Rarefied Gas Dynamics, Pacific Grove, CA, AIP Conf. Proc. Vol. 1333, pp. 595-600, July 2010.

${ }^{29}$ J. Marichalar, A. Prisbell, F. Lumpkin, and G. LeBeau, "Study of Plume Impingement Effects in the Lunar Lander Environment," 27th International Symposium on Rarefied Gas Dynamics, Pacific Grove, CA, AIP Conf. Proc. Vol. 1333, pp. 589-594, July 2010.

${ }^{30}$ R. Spores, R. Masse, S. Kimbrel, C. McLean, “Green Propellant Infusion Mission Propulsion System Development,” 50th AIAA/ASME/SAE/ASEE Joint Propulsion Conference, Cleveland, Ohio, July 2014.

${ }^{31}$ Bury, K.M., and Kerslake, T.W., "The Effect of Reaction Control System Thruster Plume Impingement on Orion Service Module Solar Array Power Production," AIAA International Energy Conversion Engineering Conference, AIAA-2008-5753, Cleveland, OH, 2008, p. 2.

${ }^{32}$ J. C. Lewis and J. T Kenny, "Sustained Load Crack Growth Design Data for Ti-6Al-4V Titanium Alloy Tanks Containing Hydrazine," AIAA Paper 76-769.

${ }^{33}$ L. R. Toth, and J. C. Lewis, "Effect of Chloride Ion Content in Unsymmetrical Dimethylhydrazine Propellant on Fracture Properties of Structural Alloys," AFRPL-TR-76-1, Jan 1976.

${ }^{34}$ J. N. Masters, W. P. Hease, and W.D. Bixler, "Fracture and Nitrogen Tetroxide/Sustained Load Flaw Growth of 6AL-4V Titanium - Final Report," N70-23205, October 1969.

${ }^{35}$ M. E. Riesco et al., "Venting and High Vacuum Performance of Low Density Multilayer Insulation" Advances in Cryogenic Engineering: Transactions of the Cryogenic Engineering Conference, CEC, Vol. 55, 2010, pages 796 to 803

${ }^{36}$ D. W. Plachta, J. R. Feller, and W. L. Johnson, "Liquid Hydrogen Active Thermal Control," CPST Technology Briefing to Industry, Glenn Research Center, Cleveland, OH, August 15, 2013.

${ }^{37}$ J. J. Wood, L. W. Foster et al., "MLI/BAC Shield Thermal and Acoustic Test," CPST Technology Briefing to Industry, Glenn Research Center, Cleveland, OH, August 15, 2013.

${ }^{38}$ J. E. Fesmire et al., Thermal Performance Testing of Cryogenic Insulation Systems. Thermal Conductivity 29. Lancaster, PA: DEStech Publications, 2008. pp. 387-396. 